This PDF is a selection from a published volume from the National Bureau of Economic Research

Volume Title: Social Security Programs and Retirement around the World: Micro-Estimation

Volume Author/Editor: Jonathan Gruber and David A. Wise, editors

Volume Publisher: University of Chicago Press

Volume ISBN: 0-226-31018-3

Volume URL: http://www.nber.org/books/grub04-1

Publication Date: January 2004

Title: Micro-Modeling of Retirement Decisions in Germany

Author: Axel Börsch-Supan, Reinhold Schnabel, Simone Kohnz, Giovanni Mastrobuoni

URL: http://www.nber.org/chapters/c10703 


\title{
Micro-Modeling of Retirement Decisions in Germany
}

\author{
Axel Börsch-Supan, Reinhold Schnabel, Simone Kohnz, \\ and Giovanni Mastrobuoni
}

\subsection{Introduction}

Germans retire early. Average retirement age is about fifty-nine-andone-half years, half a year younger than the earliest eligibility age for old-age pensions and more than five years younger than the "normal" retirement age in Germany. Early retirement is a well-appreciated social achievement among Germans, but it is costly. Since life expectancy at age sixty is about seventeen years, a year of early retirement corresponds to more than 5 percent of pension expenditures.

This paper is part of a multistage research project on the causes for and the effects of early retirement. ${ }^{1}$ Its significance stems from the mounting strain on the German public pension system. The German public pension or, as it is known in German, "public retirement insurance," was the first formal pension system when it was installed over one hundred years ago and has been a model for many social security systems in the world. It has been very successful in providing a high and reliable level of retirement income over the past one hundred years. It has survived, although under severe modifications, through World Wars I and II, the Great Depression, and, most recently, the German unification.

However, times have changed. According to recent polls, most young

Axel Börsch-Supan is director of the Mannheim Research Institute for the Economics of Aging, professor of economics at the University of Mannheim, and a research associate of the National Bureau of Economic Research (NBER). Reinhold Schnabel is professor of economics at the University of Essen. Simone Kohnz is currently a Ph.D. student at the University of Munich and was research fellow at the Mannheim Research Institute for the Economics of Aging in 2002. Giovanni Mastrobuoni is a Ph.D. student in Economics at Princeton University.

1. See the country chapters in Gruber and Wise (1999) for the first stage. 

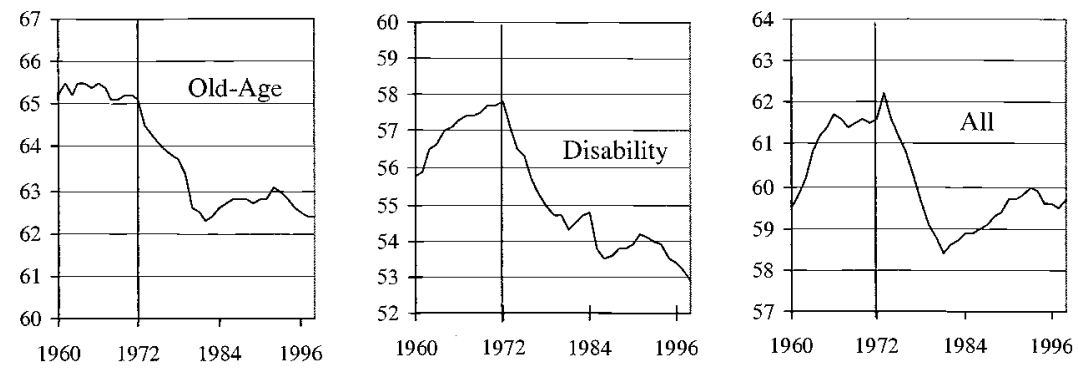

Fig. 5.1 Average age at first receipt of public pensions, 1960-1998

Source: VDR (1999), male workers only.

people do not believe that they will receive a pension that will suffice for their old-age consumption, and the number of employees that are using the few existing loopholes to escape the otherwise mandatory retirement insurance system has increased dramatically. Adding to this nervousness, Germany has experienced two major pension reforms in 1992 and 2001, each of them dubbed "century reforms," and a constant flurry of minor changes between 1992 and 2001. The German public pension model is under siege, and there appear to be two main culprits for this: negative incentive effects of the system, among them the incentives to retire early that have reduced the number of contributors and increased the number of beneficiaries (the "system-dependency ratio") since 1972, and the aging population, which will rather dramatically increase the system-dependency ratio beginning in 2015 and onward.

This paper is not the forum in which to discuss population aging and its implications on the pension system. ${ }^{2}$ Rather, we focus on the incentive effects to retire early. Figure 5.1 depicts the evolution of average retirement age among German men from 1960 through 1998, once disaggregated by old-age pensions and disability pensions, and once total.

The most obvious feature is the sudden change after 1972, when the retirement age drops sharply for both old-age and disability pensions. Within a few years, the average retirement age for old-age pensions dropped by about three years and has then stabilized. For disability pensions, we see a steady decline since 1972 that has not stopped yet. Composition effectsmainly caused by the tighter disability rules - have led to a consolidation of the total retirement age at about fifty-nine-and-one-half years.

The year 1972 marks the first major pension reform after the current pay-as-you-go (PAYG) public pension system was installed in 1957. This reform introduced a "flexible" retirement age without actuarial adjust- 
ments of pension benefits. Without going further into details-see BörschSupan and Schnabel (1998) for a more detailed description and analysisfigure 5.1 appears to be prima facie evidence for the incentives which pension rules create to retire early. ${ }^{3}$

Several formal econometric analyses based on micro-data have studied the incentive effects of the nonactuarial adjustment on early retirement (Börsch-Supan 1992; Schmidt 1995; Siddiqui 1997; and Börsch-Supan 2000c, 2001b). These studies employ variants of the micro-econometric option value analysis developed by Stock and Wise (1990). Börsch-Supan (2000c) derives from the estimates that the 1992 reform will increase the average retirement age only by about half a year and will reduce retirement before age sixty from 32 percent to about 28 percent, while a switch to a system with actuarially fair adjustment factors would shift the retirement age by about two years. Indeed, these estimates are well in line with the drop illustrated in figure 5.1. Börsch-Supan (2001b) shows that, in effect, these estimates are robust even when much more sophisticated specifications are applied.

This paper builds on these econometric analyses. Its main purpose is to provide further econometric evidence for the strength of the incentive effects to retire early, based on micro-data. It adds to the existing literature in at least four respects. First, this paper uses definitions and specifications that are comparable to the other countries in this volume. Second, the paper extends the comprehensive treatment of retirement as an option with several pathways in Börsch-Supan (2001b) beyond the standard old-age and disability pension. Third, the paper exploits as much of the sample variation as possible; specifically, we include civil servants in our estimations. Fourth and finally, we apply a "family approach" to retirement options and compute the joint incentives for husband and spouse. ${ }^{4}$

The paper is structured as follows. Sections 5.2 and 5.3 describe the institutional background for private-sector and civil servants' pensions. Section 5.4 presents data and variable specifications, section 5.5 contains our estimation results; section 5.6 explores what these estimates mean, simulates a set of pension reform steps and concludes.

\subsection{Private-Sector Pensions}

In this section we describe the German public retirement insurance (Gesetzliche Rentenversicherung or GRV), which covers about 85 percent of the German workforce. Most of these are private-sector workers, but the GRV also includes those public-sector workers who are not civil servants.

3. A competing explanation is that labor demand effects are due to rising unemployment. See Riphahn and Schmidt (1995) and Börsch-Supan (2000c), who show that there is no evidence in favor of this.

4. See Coile (1999) for the significance of this extension. 
Civil servants, about 7 percent of the workforce, have their own pension system, described in section 5.3. The self-employed, about 9 percent of the work force, are mainly self-insured although some of them also participate in the public retirement insurance system. For the average worker, occupational pensions do not play a major role in the German system of old-age provision, neither do individual retirement accounts, but there are important exceptions from this general picture. Broadly speaking, the German system is a monolith.

The following descriptions focus on the institutional rules that applied during our sample period 1984-1997 (dubbed "1972 legislation," although there have been several administrative adjustments since 1972). There have been two major pension reforms in 1992 and 2001. At several places, notably the last subsection, we briefly sketch their implications. These reforms, however, did not affect the persons in our sample.

\subsubsection{Coverage and Contributions}

The German PAYG public pension system features a very broad mandatory coverage of workers. Only the self-employed and, until 1998, workers with earnings below the official minimum-earnings threshold (Geringfügigkeitsgrenze, which is 15 percent of average monthly gross wage; below this threshold are about 5.6 percent of all workers) are not subject to mandatory coverage.

Roughly 70 percent of the budget of the German public retirement insurance is financed by contributions that are administrated like a payroll tax, levied equally on employees and employers. Total contributions in 2000 are 19.3 percent of the first DM 8,600 of monthly gross income (the upper-earnings threshold, Beitragsbemessungsgrenze, is about 180 percent of average monthly gross wage). ${ }^{5}$ Technically, contributions are split evenly between employees and employers. While the contribution rate has been fairly stable since 1970, the upper-earnings threshold has been used as a financing instrument. It is anchored to the average wage and has increased considerably faster than inflation.

Private-sector pension benefits are essentially tax free. Pension beneficiaries do not pay contributions to the pension system or to unemployment insurance. However, pensioners have to pay the equivalent of the employees' contribution to the mandatory medical insurance. The equivalent of the employers' contribution to health insurance is paid by the pension system.

The remaining approximately 30 percent of the social security budget are financed by earmarked indirect taxes (a fixed fraction of the valueadded tax and the new "eco-tax" on fossil fuel) and a subsidy from the fed-

5. This is for West Germany only; it is DM 7,200 in East Germany. One DM has a purchasing power of approximately $\$ 0.50$. 
eral government. The subsidy is also used to fine-tune the PAYG budget constraint, which has a minimal reserve of one month worth of benefits.

\subsubsection{Benefit Types}

The German public retirement insurance provides old-age pensions for workers aged sixty and older; disability benefits for workers below age sixty, which are converted to old-age pensions at age sixty-five at the latest; and survivor benefits for spouses and children. In addition, preretirement (i.e., retirement before age sixty) is possible through several mechanisms using the public transfer system, mainly unemployment compensation. We begin by describing old-age pensions.

\subsubsection{Eligibility for Benefits and Retirement Age for Old-Age Pensions}

Eligibility for benefits and the minimum retirement age depend on which type of pension the worker chooses. The German public retirement insurance distinguishes five types of old-age pensions, corresponding to normal retirement and four types of early retirement.

This complex system was introduced by the 1972 social security reform. One of the key provisions was the introduction of flexible retirement after age sixty-three with full benefits for workers with a long service history. In addition, retirement at age sixty with full benefits is possible for women, unemployed, and older disabled workers. Older disabled workers refers to those workers who cannot be appropriately employed for health or labor market reasons and are age sixty or older. There are three possible ways to claim old-age disability benefits. One has to either (a) be at least 50 percent physically disabled; (b) pass a strict earnings test; or (c) pass a much weaker earnings test. The strict earnings test is passed if the earnings capacity is reduced below the minimum-earnings threshold for any reasonable occupation (about 15 percent of average gross wage; erwerbsunfähig or EU). The weaker earnings test is passed when no vacancies for the worker's specific job description are available, and the worker has to face an earnings loss of at least 50 percent when changing to a different job (berufsunfähig or BU). As opposed to the disability insurance for workers below age sixty (see later discussion), full benefits are paid in all three cases.

Figure 5.2 shows the uptake of the various pathways, ${ }^{6}$ including the disability pathway described below (adding up to 100 percent on the vertical axis) and their changes over time (marked on the horizontal axis), mostly in response to reforms, benefit adjustments, and administrative rule changes, particularly the tightening of the disability screening process. This figure shows the multitude of possible pathways. A major undertaking of this paper is to take account of this diversity.

According to the 1992 social security reform and its subsequent modifi-

6. See Jacobs, Kohli, and Rein (1990) for this concept. 


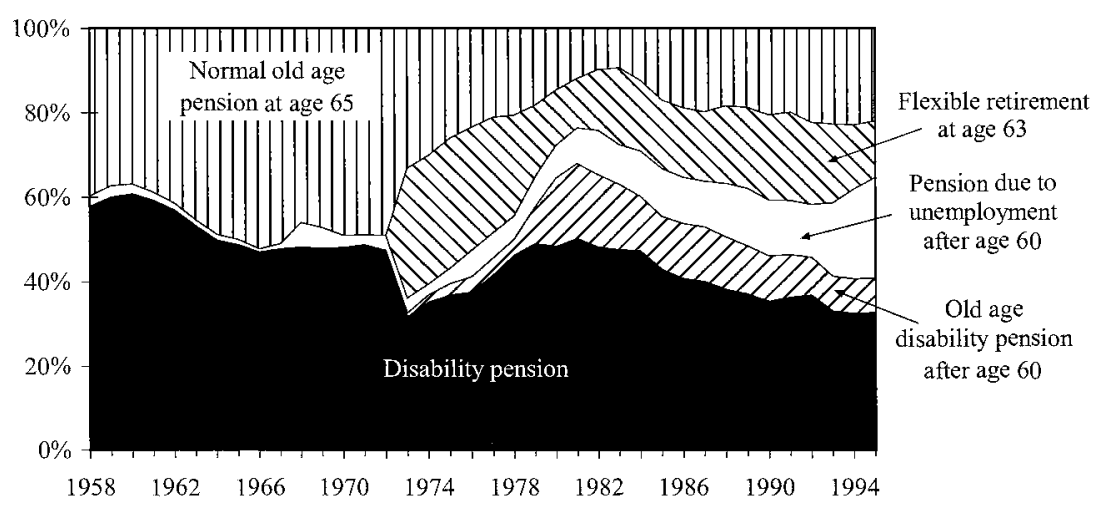

Fig. 5.2 Pathways to retirement, 1960-1995: Males

Source: Börsch-Supan and Schnabel (1999).

cations, the age limit for types of early retirement will gradually be raised to age sixty-five. These changes will be fully be phased in by the year 2004. The only distinguishing feature of types B and C of "early retirement" will then be the possibility to retire up to five years earlier than age sixty-five if a sufficient number of service years (currently thirty-five years) has been accumulated. As opposed to the pre-1992 regulations, benefits will be adjusted to a retirement age below age sixty-five in a fashion that will be described below.

\subsubsection{Benefits}

Benefits are strictly work related. The German system does not have benefits for spouses, like in the United States. ${ }^{7}$ Benefits are computed on a lifetime basis and adjusted according to the type of pension and retirement age. They are the product of four elements: (a) the employee's relativeearnings position; (b) the years of service life; (c) adjustment factors for pension type and (since the 1992 reform) retirement age; and (d) the average pension. The first three factors make up the personal pension base, while the fourth factor determines the income distribution between workers and pensioners in general.

The employee's relative-contribution position is computed by averaging their annual relative-contribution positions over the entire earnings history. In each year, the relative-contribution position is expressed as a multiple of the average annual contribution (roughly speaking, the relativeincome position). A first element of redistribution was introduced in 1972, when this multiple could not fall below 75 percent for contributions before 1972, provided a worker had a service life of at least thirty-five years. A similar rule was introduced in the 1992 reform: For contributions between 1973 and 1992, multiples below 75 percent are multiplied by 1.5 up to the

7. There are, of course, survivor benefits. 
maximum of 75 percent, effectively reducing the redistribution for workers with income positions below 50 percent.

Years of service life are years of active contributions plus years of contribution on behalf of the employee and years that are counted as service years even when no contribution were made at all. These include, for instance, years of unemployment, years of military service, three years for each child's education for one of the parents, some allowance for advanced education, and so forth, thus introducing a second element of redistribution. The official government computations, such as the official replacement rate (Rentenniveau), assume a forty-five-year contribution history for what is deemed a normal earnings history (Eckrentner). In fact, the average number of years of contributions is about thirty-eight years. Unlike the United States, there is neither an upper bound of years entering the benefit calculation, nor can workers choose certain years in their earnings history and drop others.

Since 1992, the average pension is determined by indexation to the average net labor income. This solved some of the problems that were created by indexation to gross wages between 1972 and 1992. Nevertheless, wage, rather than cost of living, indexation makes it impossible to finance the retirement burden by productivity gains.

The average pension has provided a generous benefit level for middleincome earnings. The net replacement rate for a worker with a forty-fiveyear contribution history is 70.5 percent in 1998. For the average worker with thirty-eight years of contributions, it is reduced in proportion to 59.5 percent. Unlike the United States, the German pension system has very little redistribution, as is obvious from the benefit computation. ${ }^{8}$ The low replacement rates for high incomes result from the upper limit to which earnings are subject to social security contributions - they correspond to a proportionally lower effective contribution rate.

Before 1992, adjustment of benefits to retirement age was only implicit via years of service. Because benefits are proportional to the years of service, a worker with fewer years of service will get lower benefits. With a constant income profile and forty years of service, each year of earlier retirement decreased pension benefits by 2.5 percent and vice versa.

The 1992 social security reform will change this by the year 2004. Age sixty-five will then act as the pivotal age for benefit computations. For each year of earlier retirement, up to five years and if the appropriate conditions in table 5.1 are met, benefits will be reduced by 3.6 percent (in addition to the effect of fewer service years). The 1992 reform also introduced rewards for later retirement in a systematic way. For each year of retirement postponed past the minimum age indicated in table 5.1, the pension is increased by 6 percent in addition to the natural increase by the number of service years.

Table 5.2 displays the retirement-age-specific adjustments for a worker 
Table 5.1

Old-Age Pensions (1972 legislation)

\begin{tabular}{lcccc}
\hline Pension Type & $\begin{array}{c}\text { Retirement } \\
\text { Age }\end{array}$ & $\begin{array}{c}\text { Years of } \\
\text { Service }\end{array}$ & $\begin{array}{c}\text { Additional } \\
\text { Conditions }\end{array}$ & $\begin{array}{c}\text { Earnings } \\
\text { Test }\end{array}$ \\
\hline $\begin{array}{l}\text { A: Normal } \\
\begin{array}{l}\text { B: Long service life } \\
\text { ("flexible") }\end{array}\end{array}$ & 65 & 5 & & No \\
$\begin{array}{l}\text { C: Women } \\
\text { D: Older disabled }\end{array}$ & 60 & 15 & 10 of those after age 40 & Yes \\
E: Unemployed & 60 & 35 & $\begin{array}{c}\text { Loss of at least 50\% earnings } \\
\text { capability }\end{array}$ & $\begin{array}{l}\text { Yes } \\
\text { (Yes) }\end{array}$ \\
& 60 & 15 & $\begin{array}{c}\text { 1.5 to 3 years of unemployment } \\
\text { (has changed several times) }\end{array}$ & Yes \\
\hline
\end{tabular}

Notes: This legislation was changed in the reform of 1992. It was effective until 1998.

Table 5.2 Adjustment of Public Pensions, by Retirement Age (as percentage of pension one would obtain if retired at age 65 )

\begin{tabular}{|c|c|c|c|c|c|}
\hline \multirow[b]{2}{*}{ Age } & \multicolumn{2}{|c|}{ Germany } & \multicolumn{2}{|c|}{ United States } & \multirow{2}{*}{$\frac{\text { Actuarially }}{\text { Fair }^{\mathrm{e}}}$} \\
\hline & Pre-1992a & Post-1992 ${ }^{\mathrm{b}}$ & Pre- $1983^{c}$ & Post-1983c & \\
\hline 62 & 100.0 & 89.2 & 80.0 & 77.8 & 80.5 \\
\hline 63 & 100.0 & 92.8 & 86.7 & 85.2 & 86.3 \\
\hline 64 & 100.0 & 96.4 & 94.4 & 92.6 & 92.8 \\
\hline 65 & 100.0 & 100.0 & 100.0 & 100.0 & 100.0 \\
\hline 66 & 107.2 & 106.0 & 103.0 & 105.6 & 108.1 \\
\hline 67 & 114.4 & 112.0 & 106.0 & 111.1 & 117.2 \\
\hline 68 & 114.4 & 118.0 & 109.0 & 120.0 & 127.4 \\
\hline 69 & 114.4 & 124.0 & 112.0 & 128.9 & 139.1 \\
\hline
\end{tabular}

Source: Börsch-Supan and Schnabel (1999).

${ }^{\mathrm{a}}$ GRV 1972-92.

${ }^{\mathrm{b}}$ GRV after 1992 reform has been fully phased in.

'U.S. Social Security (OASDHI) until 1983.

${ }^{d}$ U.S. Social Security after 1983 reform has been fully phased in.

'Evaluated at a 3 percent discount rate with 1992-1994 mortality risks of West German males and an annual increase in net pensions of 1 percent.

who has earnings that remain constant after age sixty. Table 5.2 relates the income for retirement at age sixty-five (normalized to 100 percent) to the income for retirement at earlier or later ages, and compares the implicit adjustments after 1972 with the total adjustments after the 1992 social security reform is fully phased in. As references, the table also displays the corresponding adjustments in the United States and actuarially fair adjustments at a 3 percent discount rate. ${ }^{9}$

9. The actuarially fair adjustments equalize the expected social security wealth for a worker with an earnings history starting at age $S$ equals 20 . A higher discount rate yields steeper adjustments. 
While neither the German nor the U.S. system were actuarially fair prior to the reforms, the public retirement system in Germany as enacted in 1972 was particularly distortive. There was less economic incentive for Americans to retire before age sixty-five and only a small disincentive to retire later than at age sixty-five after the 1983 reform, while the German social security system tilted the retirement decision heavily towards the earliest retirement age applicable. The 1992 reform has diminished but not abolished this incentive effect.

\subsubsection{Disability and Survivor Benefits}

The contributions to the German retirement insurance also finance disability benefits to workers of all ages and survivor benefits to spouses and children. In order to be eligible for disability benefits, a worker must pass one of the two earnings tests mentioned earlier for the old-age disability pension. If the stricter earnings test is passed, full benefits are paid (EU); if only the weaker earnings test is passed and some earnings capability remains, disability pensions before age sixty are only two-thirds of the applicable old-age pension (BU). In the 1970s and early 1980s, the German jurisdiction has interpreted both rules very broadly, in particular the applicability of the first rule. Moreover, jurisdiction also overruled the earnings test (see following discussion) for earnings during disability retirement. This lead to a share of EU-type disability pensions of more than 90 percent of all disability pensions. Because both rules were used as a device to keep unemployment rates down, their generous interpretation has only recently lead to stricter legislation. ${ }^{10}$

Survivor pensions are 60 percent of the husband's applicable pension for spouses that are age forty-five and over or if children are in the household (große Witwenrente), otherwise they are 25 percent (kleine Witwenrente). Survivor benefits are a large component of the public pension budget and of total pension wealth as will be shown in section 5.3. Certain earnings tests apply if the surviving spouse has her own income, e.g., her own pension. This is only relevant for a very small (below 10 percent) share of widows. Male and female survivors are treated symmetrically only recently. As mentioned before, the German system does not have a married-couple supplement for spouses of beneficiaries. However, most wives acquire their own pension by active and passive contribution (mostly years of advanced education and years of child education).

\subsubsection{Preretirement}

In addition to benefits through the public pension system, transfer payments (mainly unemployment compensation) enable what is referred to as preretirement. Labor force exit before age sixty is frequent: About 45 per- 
cent of all men call themselves retired at age fifty-nine. Only about half of them retire because of disability; the other 50 percent make use of one of the many official and unofficial preretirement schemes.

Unemployment compensation has been used as preretirement income in an unofficial scheme that induced very early retirement. Before workers could enter the public pension system at age sixty, they were paid a negotiable combination of unemployment compensation and a supplement or severance pay. At age sixty, a pension of type E (see table 5.1) could start. As the rules of type-E pensions and the duration of unemployment benefits changed, so did the unofficial retirement ages. Age fifty-six was particularly frequent in West Germany, because unemployment compensation is paid up to three years for elderly workers; it is followed by the lower unemployment aid. Earlier retirement ages could be induced by paying the worker the difference between the last salary and unemployment compensation for three years and, after these three years, by paying the difference (in yearly income) between the last salary and unemployment aid - it all depended on the "social plan," in which a firm would negotiate with the workers before restructuring the work force.

In addition, early retirement at age fifty-eight was made possible in an official preretirement scheme (Vorruhestand), in which the employer received a subsidy from unemployment insurance if a younger employee was hired. While the first (and unofficial) preretirement scheme was very popular and a convenient way to overcome the strict German labor laws, few employers used the official second scheme.

\subsubsection{Retirement Behavior}

The retirement behavior of entrants into the German public retirement insurance system has been summarized by figures 5.1 and 5.2. For West Germany, the average retirement age in 1998 was 59.7 years for men and 60.7 years for women. In the East, the average retirement age was 57.9 years for men and 58.2 years for women. The fraction of those who enter retirement through a disability pension has declined (see figure 5.2) and was 29 percent in 1998 . Only about 20 percent of all entrants used the normal pathway of an old-age pension at age sixty-five. The most popular retirement age is age sixty.

\subsubsection{Pension Reform}

During and since our sample period, there have been two major pension reforms in 1992 and 2001 and many smaller adjustments in-between. The main changes in the 1992 reform anchored benefits to net, rather than to gross, wages. This implicitly has reduced benefits since taxes and social security contributions have increased, reducing net wages, relative to gross wages. This mechanism is particularly important when the population aging will speed up. The other important change in 1992 was the introduction 
of adjustments to benefits in some (not all) cases of early retirement and a change in the normal retirement age for women. (They have been described in subsection 5.2.4.) They will be fully effective in 2017 and reduce the incentives to retire early. However, they are still not actuarially fair even at very low discount rates. ${ }^{11}$

The 2001 reform is intended to change the monolithic German system of old-age provision to a genuine multipillar system. Benefits will gradually be reduced by about 10 percent, lowering the replacement rate with respect to the average net earnings from 72 percent in 1997 to 64 percent in 2030 . The effective benefit cuts are even larger since the credit of earnings points for education and training will be greatly restricted. On the other hand, a redefinition of the official replacement rate minimizes the perception of these cuts because, defined as such, the new replacement rate will be 67 percent with respect to a smaller net earnings base. The resulting pension gap of slightly less than 20 percent of the current retirement income is supposed to be filled with occupational and individual pensions. This new pillar is not mandatory, but the required private savings will be subsidized or tax privileged. The 2001 reform does not change the normal retirement age or the adjustment factors concerning the early retirement age that provide the large incentives to retire early, which is the main subject of this paper.

\subsection{Public-Sector Pensions}

There are two types of workers in the public sector: civil servants and other public-sector workers. As already mentioned, the latter are part of the same system as the private-sector workers described in the previous section. In addition, they participate in a supplemental system that resembles occupational pensions elsewhere and raises the pensions of public-sector workers to the level of civil servants.

Civil servants do not pay explicit contributions for their pensions, as the other employees in the private- and public-sectors do. ${ }^{12}$ Instead, the gross wage for civil servants is lower than the gross wage of other public-sector employees with a comparable education. Civil servants acquire pension claims that are very generous compared to workers in the private sector.

\subsubsection{Eligibility: Pathways to Retirement for Civil Servants}

There are three pathways for civil servants: the standard, the early, and the disability retirement option. The standard retirement age is sixty-five. Before 1 July 1997 the early retirement age for civil servants was sixty-two

11. Not even at zero is it actuarially fair.

12. Civil servants are also exempt from unemployment-insurance contributions since civil servants have a lifetime job guarantee. The government pays a certain fraction of health expenses of the civil servant and their dependents (ranging from 50 to 80 percent). The rest has to be covered by private insurance. 
and thus one year less than the early retirement age in the social security system. In 1997, early retirement age was raised to sixty-three. Discount factors for early retirement are phasing in linearly between the years 1998 and 2003 and will reach 0.3 percentage points per month of early retirement, the same as in the private sector and substantially smaller than actuarially fair. Since our sample covers the years 1984 to 1997, these changes of rules do not play a role in our analysis. ${ }^{13}$

Filing for disability is a third pathway to retirement for civil servants. In the case of disability, a civil servant receives a pension that is based on their previous salary. The replacement rate depends on the number of service years reached before disability retirement and the number of service years that could potentially have been accumulated up to age sixty. For those who did not reach the maximum replacement rate before disability, one additional year of service raises the replacement rate by only $1 / 3$ percentage point per year.

\subsubsection{Computation of Pensions}

The standard pension benefit for civil servants is the product of three elements: (a) the last gross earnings level; (b) the replacement rate as function of service years, and (c) the new adjustment factors to early retirement. As described previously, this third component does not affect our sample persons. There are three crucial differences between civil servants' pensions and private-sector benefits. First, the benefit base is gross income, rather than net income. In turn, civil servants' pensions are taxed like any other income. Finally, the benefit base is the last salary rather than the lifetime average.

In the following, we concentrate on describing how the system worked for the sample period 1984-1997. Benefits are anchored to the earnings in the last position and then updated annually by the growth rate of the net earnings of active civil servants. If the last position was reached within the two years preceding retirement, the pension is based on the previous lower position. Due to the difference in the benefit base, gross pensions of civil servants are approximately 25 percent higher (other things being equal) than in the private sector.

The maximum replacement rate is 75 percent of gross earnings which is considerably higher than the official replacement rate of the private-sector system, which is around 70 percent of net earnings. The replacement rate depends on the years of service. High school and college education, military service, and other work in the public sector are also counted as service years. For retirement after June 1997, the college education credit is limited to three years.

13. Very specific rules apply to some civil servants. For example, the regular retirement age for police officers is age sixty; for soldiers it is even lower and depends on their rank. 
Before 1992, the replacement rate was a nonlinear function of service years. The replacement rate started at a value of 35 percent for all civil servants with at least five years of service. For each additional year of service between the tenth and the twenty-fifth year, the increment was 2 percentage points. From the twenty-fifth to the thirty-fifth year the annual increment was 1 percent. Thus, the maximum replacement rate of 75 percent was reached with thirty-five service years under the old rule. This is much more generous than the private-sector replacement rate of 70 percent that requires forty-five years of service.

For persons retiring after 1 January 1992, the replacement rate grows by 1.88 percentage points for each year of service. Thus, the maximum value is reached after forty years of service. However, there are transitional modifications to that simple rule. First, civil servants who reach the standard retirement age (usually age sixty-five) before 1 January 2002 are not affected at all. Second, for younger civil servants, all claims that have been acquired before 1992 are conserved. These persons gain 1 additional percentage point per year from 1992 onward. All persons who have acquired twenty-five service years before 1992 have reached 65 percentage points and also would have gained only 1 additional point per year under the old rule. Only persons with less than twenty-five service years in 1991 can be made worse off by the reform. The new proportional rule only applies if it generates a higher replacement rate than the transitional rule. Our calculations of pension wealth use these institutional changes, but only a few special cases are affected.

The generosity of gross pensions received by civil servants vis-á-vis the private-sector workers is only partially offset by the preferential tax treatment of private-sector pensions. Since civil servants' pensions are taxed according to the German comprehensive income taxation, the net replacement rates of civil service pension recipients depends on their position in the highly progressive tax schedule. In general, the net replacement rate, with respect to the preretirement net earnings, is higher than 75 percent and thus considerably more generous than in the private sector.

\subsubsection{Incentives to Retire}

In our sample, most civil servants have reached the maximum replacement rate by the age of fifty-four. Persons who have started to work in the public sector before the age of twenty-three have reached a replacement rate of 75 percent, when taking into account the disability rules. This also holds for civil servants, who-like professors - receive lifetime tenure late in their life cycle. For those groups, the starting age is usually set at twenty-one. Additional years of service beyond the age of fifty-four increase pensions only if the civil servant is promoted to a position with a higher salary. Retirement incentives therefore strongly depend on promotion expectations.

For persons who cannot expect to be promoted after age fifty-four, the 
pension accrual is zero or very small. For those who have already reached the replacement rate of 75 percent, the accrual of the present discounted pension wealth is negative. Since the replacement rate is 75 percent of the gross earnings in the last position before retirement, the negative accrual of postponing retirement by one year is simply 75 percent of the last gross earnings. This is equivalent to a 75 percent tax on earnings.

For persons who expect to climb another step in the hierarchy, the gross wage increase is, on average, 10.5 percent. This raises the pension by approximately 10 percent. In order to cash in the higher pension, the civil servant has to defer retirement by at least one year. ${ }^{14}$ In this extreme case the social security wealth increases 10 percent through the effect of higher pensions and decreases by 5 percent through the effect of pension deferral. In this extreme case, the pension accrual is positive. If the civil servant has to wait several years for the next promotion (or for the promotion to have an effect on pension claims), the accrual of working becomes negative.

The dependency on promotion expectations makes modeling the incentive effects for civil servants very hard, since the researcher needs information on the career prospects of the respondent. We do not have such information in our data and must therefore ignore the effect of potential promotions.

\subsubsection{Retirement Behavior}

The retirement behavior of civil servants reflects the very generous disability and early retirement rules. The average retirement age for civil servants in the year 1993 was age 58.9 and thus about one year lower than in the private sector (see section 5.2.7). Disability is the most important pathway to retirement for civil servants - 40 percent of those who retired in the year 1993 used disability retirement. Almost one-third used the early retirement option at the age of sixty-two. Only about 20 percent of civil servants retired at the regular retirement age of sixty-five.

\subsection{Data and Variable Specification}

Our main data source is the German Socio-Economic Panel (GSOEP), described subsequently. The remaining subsections are devoted to the variable construction, notably the definition of retirement status, which acts as our dependent variable, and the incentive variables, which act as our main explanatory variables. Aggregate information is provided by the German retirement insurance organization (Verband deutscher Versicherungträger or VDR), which publishes annual statistics on average earnings, system entries, retirement age, and the like (Rentenversicherung in Zeitreihen), and by

14. For the higher earnings to take effect on pensions, it is usually required to work several years after the promotion. 
the Labor Ministry (Bundesministerium für Arbeit und Sozialordnung; BMA 1999).

\subsubsection{The German Socio-Economic Panel}

The GSOEP is an annual panel study of some 6,000 households and some 15,000 individuals. The data are gathered by the German Institute for Economic Research (DIW). The GSOEP is a panel survey of private households. Its design closely corresponds to the U.S. Panel Study of Income Dynamics (PSID). ${ }^{15}$ The GSOEP includes carefully designed household weights that match the data with the German Mikrozensus. The panel started in 1984; we use fourteen annual waves through 1997.

In 1997, the GSOEP had four subsamples: (a) West German citizens $(9,000$ persons in 1984); (b) Foreign workers from Spain, Italy, Greece, Turkey, and former Yugoslavia residing in West Germany (3,000 persons in 1984, oversampled); (c) East German citizens (4,000 persons sampled from 1991 onward); and (d) Germans who have remigrated (mainly from Romania and the former Soviet Union; 1,000 persons sampled in 1995). We draw our working sample from samples (a) and (b) since the labor supply patterns of East Germans and remigrants are substantially different from residents in West Germany so that pooling these samples is not warranted. ${ }^{16}$

We constructed a equal-sided unbalanced panel of all persons aged fiftyfive through seventy from subsamples (a) and (b) for whom earnings data is available. ${ }^{17}$ This panel includes 2,223 individuals with 14,401 observations. Average observation time is six-and-one-half years. The panel is left censored, as we include only persons who have worked at least one year during our time window in order to reconstruct an earning history. There is only a little right censoring due to missing interviews. Specifically, foreign workers often leave Germany after retirement. However, since this affects only a few cases, we did not model this censoring. The sample contains private-sector workers, civil servants and other public-sector workers, and the self-employed.

The GSOEP data provide a detailed account of income and employment status. Since the GSOEP performs personal interviews with each member aged seventeen and older in the household, we have the same information on husbands and spouses. The personal information includes labor market status, gross and net income, hours worked, education, and marital status

15. Burkhauser (1991) provides an English-language description, code books, and links to an internationally accessible GSOEP version. Börsch-Supan (2000b) discusses the merits and limits of the GSOEP data for studies of retirement behavior.

16. Schmähl (1991) provides a narrative of the transition.

17. We excluded East Germany because its retirement patterns are dominated by the transition problems to a market economy. See Börsch-Supan and Schmidt (1996) for a comparison. 
Table 5.3 Descriptive Statistics of Main Variables

\begin{tabular}{lcrcrr}
\hline Variable & $\begin{array}{c}\text { Valid } \\
\text { Observations }\end{array}$ & Mean & $\begin{array}{c}\text { Standard } \\
\text { Deviation }\end{array}$ & Minimum & Maximum \\
\hline Age & 14,401 & 59.77 & 4.88 & 53 & 70 \\
Health & 14,401 & 8.09 & 3.05 & 0 & 10 \\
Married & 14,401 & $86 \%$ & $34 \%$ & 0 & 1 \\
College & 14,401 & $11 \%$ & $31 \%$ & 0 & 1 \\
Skilled & 14,401 & $86 \%$ & $58 \%$ & 0 & 2 \\
Homeowner & 14,398 & $52 \%$ & $50 \%$ & 0 & 1 \\
No wealth & 14,312 & $11 \%$ & $31 \%$ & 0 & 1 \\
Financial assets & 14,401 & $22 \%$ & $42 \%$ & 0 & 1 \\
Experience & 14,401 & 450.29 & 96.01 & 0 & 646 \\
Former self-employed & 14,401 & $9 \%$ & $29 \%$ & 0 & 1 \\
Former civil servant & 14,359 & $8 \%$ & $27 \%$ & 0 & 1 \\
Children in household & 14,401 & $33 \%$ & $47 \%$ & 0 & 1 \\
\hline
\end{tabular}

Source: GSOEP, working sample of males, 1984-97 (available at http://www.diw-berlin.de/ gsoep).

but only a subjective indicator of health (plus disability status, and number of doctor and hospital visits). The GSOEP also has a very detailed labor market calendar that provides monthly information on the labor market status (full-time, part-time, retired, unemployed, and education) and its corresponding income for each sample person. This detailed information during the sample period is augmented by a retrospective history of labor force participation that starts with age fifteen. It carries the annual labor market status (full-time, part-time, unemployed, out-of-labor force, and so forth) but has no retrospect earnings information.

Table 5.3 presents the descriptive statistics of the most common socioeconomic variables in our working sample.

\subsubsection{Construction of Earnings Histories}

Since the benefit formula for private-sector pensions depends on earnings points computed from relative-income positions, and since civil servants' pensions depend on the last salary, we do not need a complete earnings history of our sample persons. Information on the earnings position in each year relative to the aggregate average of that year is sufficient. We have this information for the sample period but not for earlier years. We therefore estimate the average relative earnings position (EP) using all nonretired, full- or part-time workers in the sample who have a positive wage. We fit a fixed-effects model for EP. The fixed effects absorb the constant covariates (e.g., education, marital status, and race). All aggregate yearspecific covariates drop out since we estimate the relative earnings position. This procedure makes the most efficient use of our earnings data.

In the forward projection, we need a forecast of the absolute earnings 
level. In retrospect, we recover this by multiplying EP, the average relative earnings position, with the aggregate level of earnings, which we take from the VDR statistics. For future years, we assume a 1 percent real wage growth, corresponding to the average over the last twenty-five years.

\subsubsection{Definition of Retirement Status}

The definition of the retirement status is problematic. Retirement definitions commonly employed in the literature include the retirement status self-reported by the respondent. Few work hours or the receipt of retirement benefits are among other definitions. In many countries (e.g., the United States; see Rust 1990), these definitions do not coincide for a large fraction of old-age workers. The problem is somewhat less severe in Germany, although there are some differences such as the more distinct spikes at the legal ages (described in table 5.1), as can be seen from figure 5.3.

The persons in our sample appear to have a very general notion of retirement since, when asked about their labor market status, they consider the receipt of benefits from preretirement schemes as well as from the formal retirement programs as retirement. It seems as if they consider different programs as close substitutes. For instance, persons who receive severance pay from their former employers plus unemployment compensation generally claim to be retired. Moreover, our sample persons rarely report significant hours worked after the receipt of pension benefits.

Our first measure of retirement (definition I) is thus the self-assessment as retired, and our results presented below are based on this definition. One additional reason for treating this as retirement is the fact that, after giving up the career job, there is no choice left. For instance, persons in preretirement schemes are automatically shifted from unemployment benefits to old-age pensions of type E (see table 5.1) at age sixty.

We also tried out other definitions. ${ }^{18}$ For instance, we know whether or not persons received formal pension benefits. A definition based on this excludes some forms of early retirement (definition II). We then add persons to definition I who receive formal pensions but do not consider themselves as being retired (e.g., many of the self-employed). This definition III (the joint set of I and II) is the broadest definition.

\subsubsection{Handling of Multiple Retirement Programs}

At least theoretically, a worker at age fifty-five has the choice between three retirement programs:

- Old-age pensions starting at age sixty,

- Disability pensions, and

- Preretirement schemes.

18. Using one of the other measures does not change the qualitative results. We find that the first measure of retirement works best. 


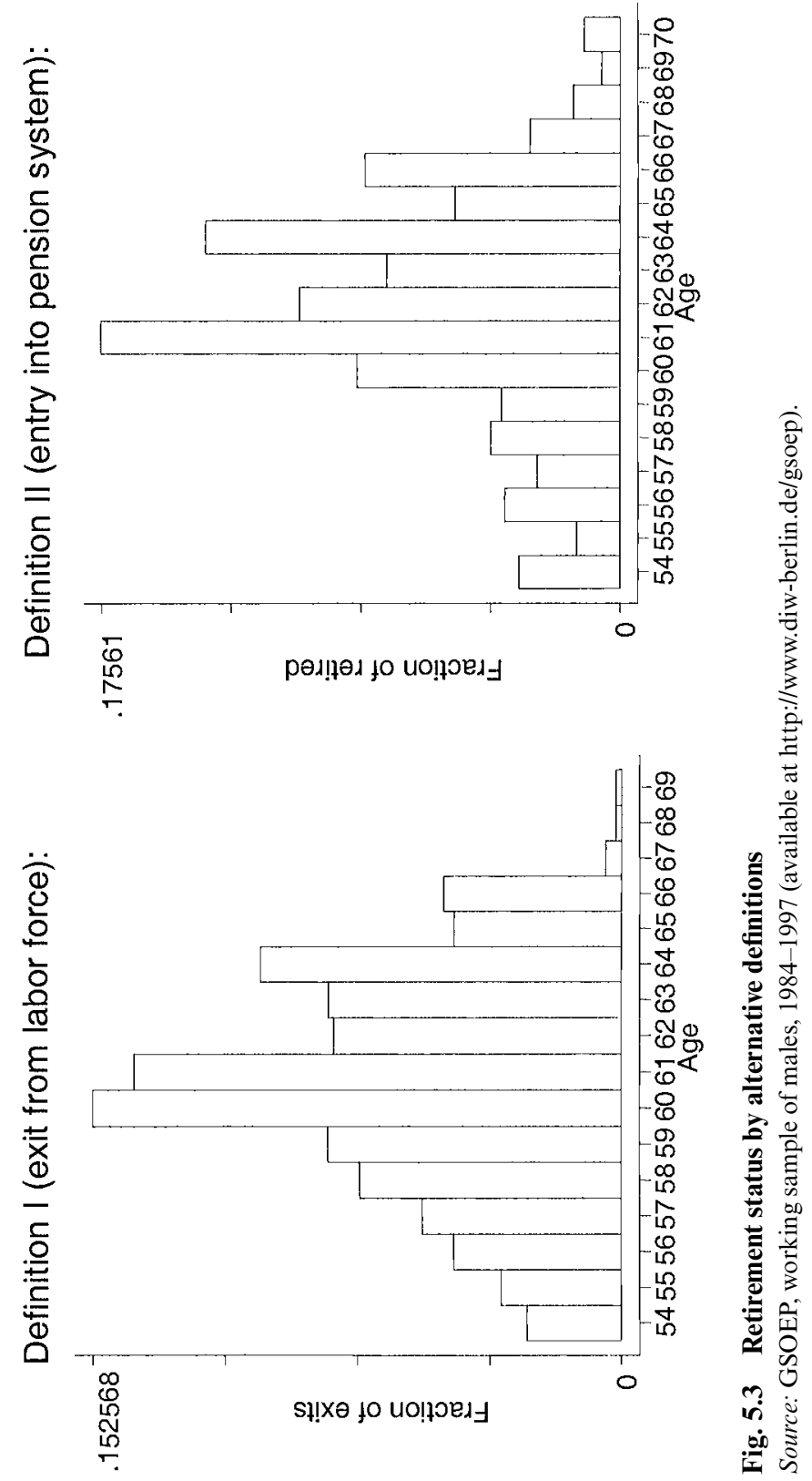


The set of choices is actually larger because some of these programs have several branch programs (e.g., within old-age pensions there are unemployment, long-service life, and so on), as depicted in figure 5.2. We refer to these choices as pathways, as we have done in figure 5.2. It is important to notice that all of these pathways pay the same benefit once a person is eligible. ${ }^{19}$

In practice, there is no free choice since most of these pathways are subject to eligibility criteria. Among those, we distinguish between "strict eligibility rules" that are tied to objective variables, such as age, gender, and previous contribution history, and "soft eligibility rules" that are subject to discretionary decisions, notably the determination of a workers' disability status. ${ }^{20}$

In the construction of social security wealth and the incentive variables (see later discussion), we need to compute expected pension benefits, which depend on the choice of pathway. We used two methods. The first method considers only strict eligibility, implicitly assuming that every individual who wants to obtain a disability pension will eventually be granted one. Hence, expected benefits at a given age are zero if the person is not eligible to any of the pathways, otherwise the (common) benefit for that given age is assumed. For example, those self-employed who pay voluntary contributions are only eligible for early retirement — namely disability - if they have contributed continuously since 1984 (the date of a major reform of voluntary participation), otherwise they can retire at the age of sixty-three at the earliest. ${ }^{21}$ In the latter case, the pension will be zero for all retirement ages below sixty-three.

The second method weights the benefits by its observed frequency. Let's suppose, the observed frequency of disability status at age fifty-nine is 33 percent, and the sample person is not eligible for any other pathway at that age. Then expected benefits at age fifty-nine for this person will be a third of the (common) benefit level. Börsch-Supan (2001b) explores the sensitivity of estimation results to these two methods, and provides an instrumental-variable interpretation of the second method. This second method is our method of choice and the only one reported in this paper.

\subsubsection{Construction of Social Security Wealth}

A key statistic to measure the incentives to retire early is the change in the net present value of all future benefits when retirement is postponed. In a slight misuse of terminology, we call the net present value of all future benefits "social security wealth" (SSW) for both private-sector and civil

19. Strictly speaking, preretirement programs can have any benefit level because they are negotiated between workers and employers. In practice, however, the outcome of these negotiations is guided by the public insurance benefits.

20. Disability depends on health as well as labor market characteristics.

21. See Schnabel (1999) for details. 
servants' pensions. If SSW declines because the increase in the annual pension due to postponement of retirement is not large enough to offset the shorter time of pension receipt, workers have a financial incentive to retire earlier.

We define SSW as the expected present discounted value of benefits (YRET) minus applicable contributions that are levied on gross earnings $(c \cdot$ YLAB). Seen from the perspective of a worker who is $S$ years old and plans to retire at age $R, \mathrm{SSW}$ is

$$
\operatorname{SSW}_{S}(R)=\sum_{t=R}^{\infty} \operatorname{YRET}_{t}(R) \cdot a_{t} \cdot \delta^{t-S}-\sum_{t=S}^{R-1} c \cdot \mathrm{YLAB}_{t} \cdot a_{t} \cdot \delta^{t-S} .
$$

SSW: net present discounted value of retirement benefits

$S$ : planning age

$R$ : retirement age

$\mathrm{YLAB}_{t}$ : gross labor income at age $t$

$\operatorname{YRET}_{t}(R)$ : net pension income at age $t$ for retirement at age $R$

$c_{t}$ : contribution rate to pension system at age $t$

$a_{t}$ : probability to survive at least until age $t$ given survival until age $S$

$\delta$ : discount factor $=1 /(1+r)$

We choose the usual discount rate of 3 percent. Conditional survival probabilities are computed from the standard life tables of the German Bureau of the Census (Statistisches Bundesamt), and SSW depends also on the joint survival probabilities of spouses through survivor pensions. We assume independence of survival of spouses to compute the joint probability.

We also have to predict future contribution rates and pensions. In order to obtain consistent policy simulations, they are simulated using the macro-economic pension model underlying Börsch-Supan (1995). This internal consistency is important. Assume a policy proposal that reduces the replacement rate by 20 percent. This immediately lowers the contribution rates by 20 percent if the system is PAYG and financed through contributions. The effect on SSW is ambiguous and varies by cohort.

Table 5.4 shows the average SSW in our sample and its change for each individual - the accrual of social security when retirement is postponed by one year. Note that the averages in the right-side panel are not the first differences of the average SSW in the left-side panel since the aggregate figures relate to different individuals in our unbalanced panel.

\subsubsection{Specification of Incentive Variables}

We computed five different incentives measures.

- ACCRUAL: the accrual of SSW if retirement is postponed by one year

- ACCRUALRATE: the accrual divided by the level of SSW 
Social Security Wealth and Its Accrual

\begin{tabular}{|c|c|c|c|c|c|c|}
\hline \multirow[b]{2}{*}{ Age } & \multicolumn{3}{|c|}{ SSW } & \multicolumn{3}{|c|}{ Accrual } \\
\hline & Mean & SD & $N$ & Mean & SD & $N$ \\
\hline 54 & 167.209 & 82.603 & 913 & -10.084 & 5.083 & 913 \\
\hline 55 & 169.280 & 80.628 & 948 & -10.494 & 5.175 & 948 \\
\hline 56 & 166.391 & 80.242 & 930 & -8.327 & 4.356 & 930 \\
\hline 57 & 168.211 & 80.550 & 885 & -8.730 & 4.651 & 885 \\
\hline 58 & 171.161 & 81.672 & 812 & -8.991 & 4.612 & 812 \\
\hline 59 & 170.002 & 81.828 & 736 & -9.360 & 4.713 & 736 \\
\hline 60 & 172.426 & 80.792 & 656 & -8.565 & 4.565 & 656 \\
\hline 61 & 175.892 & 81.324 & 572 & -8.929 & 4.690 & 572 \\
\hline 62 & 182.616 & 77.848 & 507 & -9.064 & 4.780 & 507 \\
\hline 63 & 191.603 & 75.784 & 434 & -10.997 & 4.302 & 434 \\
\hline 64 & 194.370 & 76.811 & 375 & -11.643 & 4.512 & 375 \\
\hline 65 & 194.654 & 76.697 & 325 & -12.149 & 4.652 & 325 \\
\hline 66 & 197.866 & 76.820 & 275 & -12.855 & 4.846 & 275 \\
\hline 67 & 197.180 & 76.052 & 225 & -13.374 & 5.038 & 225 \\
\hline 68 & 196.372 & 77.633 & 182 & -13.869 & 5.330 & 182 \\
\hline 69 & 196.469 & 78.187 & 144 & -14.424 & 5.637 & 144 \\
\hline Total & 175.948 & 80.691 & 8919 & -9.908 & 4.995 & 8919 \\
\hline
\end{tabular}

Note: All figures in $€ 1995$ ( $€ 1$ has a purchasing power of about US\$1.00) SD = standard deviation; $N=$ number of observations.

- TAXRATE: the accrual divided by the (potential) gross earnings during the year of postponement

- PEAKVAL: the maximum of future SSW over all possible retirement ages minus the SSW for immediate retirement

- OPTVAL: the option value of postponing retirement by one year

The pension-wealth accrual function, a function of the retirement age $R$, is the change in SSW when retirement is postponed from age $R-1$ to age $R$. We have seen this first incentive variable already in table 5.4. We convert this variable into a rate by defining

$$
\operatorname{ACCR}_{S}(R)=\frac{\operatorname{SSW}_{S}(R)-\operatorname{SSW}_{S}(R-1)}{\operatorname{SSW}_{S}(R-1)},
$$

which is displayed in table 5.5. The lack of actuarial fairness of the German public pension system creates a negative accrual of pension wealth between 5 and 8 percent during the early retirement window when retirement is postponed by one year. The average loss in our sample is about DM 10,000 (roughly US $\$ 5,000$ at purchasing power parity).

A negative accrual can be interpreted as a tax on further labor force participation. We therefore compute as an implicit tax rate the ratio of the (negative) SSW accrual to the gross wage (YLAB) that workers would earn if they postponed retirement to age $R$. 
Table 5.5

Accrual Rates and Implicit Tax Rates

\begin{tabular}{lccccccc}
\hline & \multicolumn{3}{c}{ Accrual Rate } & & \multicolumn{3}{c}{ Implicit Tax Rate } \\
\cline { 2 - 3 } \cline { 7 - 8 } Age & Mean (\%) & SD (\%) & $N$ & & Mean (\%) & SD (\%) & $N$ \\
\hline 54 & -7.7 & 15.1 & 885 & & 34.4 & 13.5 & 886 \\
55 & -8.3 & 16.6 & 927 & & 35.7 & 13.0 & 923 \\
56 & -6.9 & 14.4 & 904 & & 28.6 & 11.6 & 908 \\
57 & -7.7 & 17.3 & 862 & & 29.6 & 11.8 & 866 \\
58 & -7.2 & 14.3 & 788 & & 30.4 & 11.4 & 798 \\
59 & -8.2 & 18.2 & 711 & & 31.9 & 11.6 & 726 \\
60 & -8.0 & 20.3 & 637 & & 29.4 & 11.4 & 648 \\
61 & -7.6 & 20.2 & 553 & & 30.6 & 11.0 & 568 \\
62 & -5.0 & 1.7 & 493 & & 31.8 & 11.7 & 502 \\
63 & -5.8 & 0.4 & 432 & & 37.9 & 6.8 & 431 \\
64 & -6.0 & 0.4 & 374 & & 40.1 & 7.0 & 374 \\
65 & -6.3 & 0.4 & 325 & & 42.2 & 6.6 & 325 \\
66 & -6.5 & 0.5 & 275 & & 44.5 & 6.7 & 275 \\
67 & -6.8 & 0.5 & 225 & & 47.0 & 7.0 & 225 \\
68 & -7.1 & 0.5 & 182 & & 49.6 & 7.5 & 182 \\
69 & -7.4 & 0.5 & 144 & & 51.8 & 7.1 & 143 \\
Total & -7.2 & 14.3 & 8717 & 34.1 & 12.4 & 8780 \\
\hline
\end{tabular}

Note: $\mathrm{SD}=$ standard deviation; $N=$ number of observations.

$$
\operatorname{TAXR}_{S}(R)=-\frac{\operatorname{SSW}_{S}(R)-\operatorname{SSW}_{S}(R-1)}{\mathrm{YLAB}_{R}}
$$

This implicit tax rate can be rewritten as the product of two terms. The first term represents the effect of postponing retirement through mortality, discounting, and the adjustment of benefits to retirement age, while the second term is the net replacement rate.

$$
\begin{gathered}
\frac{\mathrm{YRET}_{R}}{\mathrm{YLAB}_{R}^{\mathrm{NET}}} \\
\operatorname{TAXR}_{S}(R)=\left[a_{R} \cdot \delta \cdot(\psi-1)-1\right] \cdot \mathrm{REPL}_{R}
\end{gathered}
$$

If benefits are actuarially fair in a financial sense, $\psi=1+1 / a_{R} \cdot \delta$, and the resulting tax rate is zero. This is not the case in Germany (see table 5.5). It shows that the early retirement incentives in Germany have been strong. The tax rate at age sixty was about 30 percent, and increased with the retirement age to exceed 40 percent at age sixty-five. These numbers refer to the pre-1992 legislation applicable to our sample. Today's implicit tax rates are about half of those in table 5.5 (see Börsch-Supan and Schnabel 1999).

These first three measures of one-year accrual only account for the immediate benefit to working an additional year. But an additional year of work also sustains the option of retiring at an even later date. The value of this choice can be important if there are large nonlinearities in the accrual 
Peak Value and Option Value

\begin{tabular}{|c|c|c|c|c|c|c|}
\hline \multirow[b]{2}{*}{ Age } & \multicolumn{3}{|c|}{ Peak Value } & \multicolumn{3}{|c|}{ Option Value } \\
\hline & Mean & SD & $N$ & Mean & SD & $N$ \\
\hline 54 & -10.084 & 5.085 & 913 & 66.414 & 111.233 & 913 \\
\hline 55 & -10.493 & 5.176 & 948 & 61.179 & 101.163 & 948 \\
\hline 56 & -8.326 & 4.357 & 930 & 59.015 & 93.312 & 930 \\
\hline 57 & -8.728 & 4.652 & 885 & 55.770 & 118.974 & 885 \\
\hline 58 & -8.986 & 4.622 & 812 & 49.709 & 115.357 & 812 \\
\hline 59 & -9.320 & 4.764 & 736 & 42.628 & 98.487 & 736 \\
\hline 60 & -8.531 & 4.612 & 656 & 33.888 & 51.254 & 656 \\
\hline 61 & -8.904 & 4.717 & 572 & 25.936 & 44.513 & 572 \\
\hline 62 & -9.064 & 4.780 & 507 & 15.646 & 33.281 & 507 \\
\hline 63 & -10.997 & 4.302 & 434 & 5.900 & 16.255 & 434 \\
\hline 64 & -11.643 & 4.512 & 375 & 2.806 & 12.175 & 375 \\
\hline 65 & -12.149 & 4.652 & 325 & 0.428 & 7.975 & 325 \\
\hline 66 & -12.855 & 4.846 & 275 & -1.341 & 6.873 & 275 \\
\hline 67 & -13.374 & 5.038 & 225 & -3.188 & 5.724 & 225 \\
\hline 68 & -13.869 & 5.330 & 182 & -4.984 & 4.855 & 182 \\
\hline 69 & -14.424 & 5.637 & 144 & -6.642 & 4.029 & 144 \\
\hline Total & -9.900 & 5.007 & 8919 & 38.167 & 87.540 & 8919 \\
\hline
\end{tabular}

Note: See table 5.4 .

profile. For example, if there is a small negative accrual at age fifty-nine, but a large positive accrual at age sixty, it would be misleading to say that the system induces retirement at age fifty-nine; the disincentive to work at that age is dominated by incentives to work at age sixty.

One way of capturing this possibility is to use the "peak value" calculation suggested by Coile and Gruber (1999). Rather than taking the difference between SSW today and next year, peak value takes the difference between SSW today and in the year in which the expected value of SSW is maximized:

$$
\operatorname{PEAKVAL}_{S}(R)=\operatorname{SSW}_{S}(R)-\max _{T>R}\left[\mathrm{SSW}_{S}(T)\right] .
$$

This measure therefore captures the tradeoff between retiring today and working until a year with a much higher SSW. In years beyond the year in which SSW peaks, this calculation collapses to the simple one-year accrual variable. In fact, PEAKVAL turns out to be virtually identical to ACCRUAL since pension accrual is negative in most cases for the whole sequence of retirement ages (see the averages in table 5.6).

All these measures include the financial aspects of the retirement decision only. Alternatively, one might consider the consumption utility of net earnings and pension benefits and also account for the utility aspects of the labor-for-leisure trade-off. To this end, we employ as the fifth and final incentive variable the option value to postpone retirement (Stock and Wise 


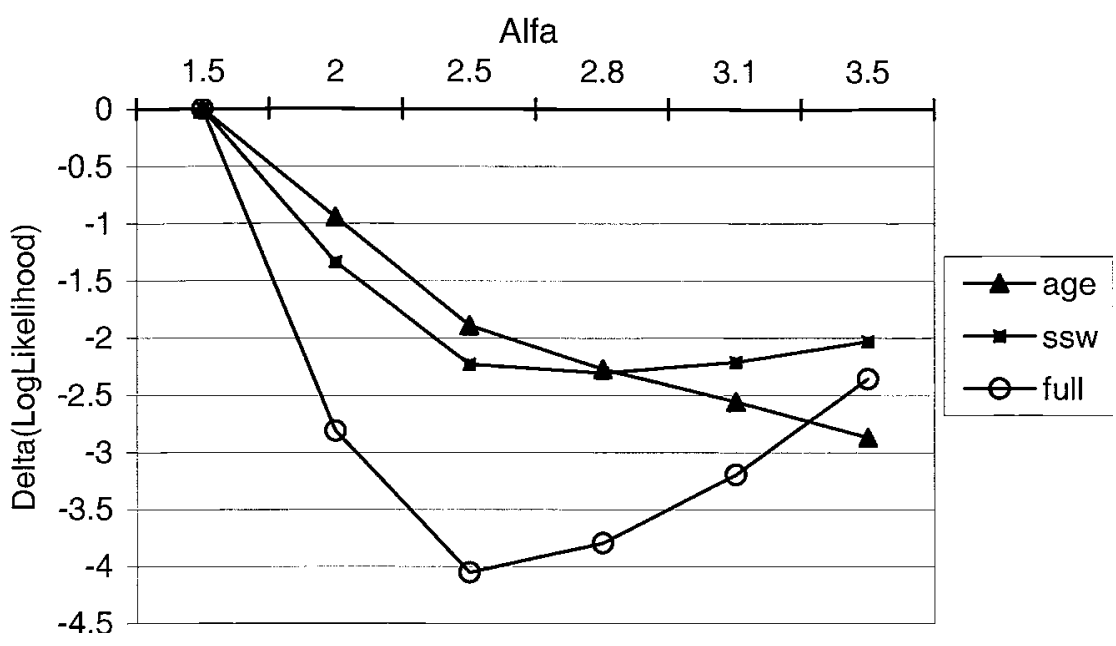

Fig. 5.4 Grid search for three estimation variants

Source: Authors' estimates based on GSOEP panel of males (available at http://www. diw-berlin.de/gsoep). See text for explanation of legend.

1990). This value expresses for each retirement age the trade-off between retiring now (resulting in a stream of utility that depends on this retirement age) and keeping all options open for some later retirement date (with associated streams of utility for all possible later retirement ages).

Let $V_{t}(R)$ denote the expected discounted future utility at age $t$ if the worker retires at age $R$, specified as follows:

$$
V_{t}(R)=\sum_{s=t}^{R-1} u\left(\mathrm{YLAB}_{s}^{\mathrm{NET}}\right) \cdot a_{s} \cdot \delta^{s-t}+\alpha \sum_{s=R}^{\infty} u\left(\operatorname{YRET}_{s}(R)\right) \cdot a_{s} \cdot \delta^{s-t} .
$$

$\mathrm{YLAB}_{s}^{\mathrm{NET}}=$ after-tax labor income at age $s, s=t \ldots R-1$

$\operatorname{YRET}_{s}(R)=$ pension income at age $s, s>R$

$R=$ retirement age

$\alpha=$ marginal utility of leisure (to be estimated)

$a=$ probability to survive at least until age $s$

$\delta=$ discount factor $=1 /(1+r)$

Utility from consumption is represented by an isoelastic utility function in after-tax income, $u(Y)=Y^{\gamma}$. (Remember that pension income in Germany is effectively untaxed.) To capture utility from leisure, utility during retirement is weighted by $\alpha>1$, where $1 / \alpha$ is the marginal disutility of work.

We employed a grid search for the parameter $\alpha$, applied to three specifications (see figure 5.4). The parameter gets smaller as more covariates are used: It is larger than 4 if only a second-order age polynomial is included (plus option value), 2.8 if initial SSW is added, and 2.5 if a large set of regressors including a full set of age dummies is added (see table 5.7). 
Definitions of Other Explanatory Variables

\begin{tabular}{ll}
\hline Age & Age of person \\
Married & Marital status: $1=$ married, $0=$ not married \\
Health & $0=$ poor, $\ldots, 10=$ excellent \\
College & $1=$ college degree, $0=$ else \\
Medium skilled & $1=$ medium skilled (only vocational training or high school) \\
Homeowner & $1=$ homeowner \\
No assets & $1=$ no wealth \\
Financial assets & $1=$ owner of financial assets \\
Exp & Work experience \\
Yhat & Estimated labor income \\
Former self-employed & Self-employed before retirement \\
Former civil servant & Civil servant before retirement \\
Kids & Children in household \\
\hline
\end{tabular}

The option value for a specific age is defined as the difference between the maximum attainable consumption utility of the worker postpones retirement to some later year minus the utility of consumption that the worker can afford if the worker would retire now. Let $R^{*}(t)$ denote the optimal retirement age if the worker postpones retirement past age $t$, that is, $\max \left(V_{t}(r)\right)$ for $r>t$. With this notation, the option value is

$$
G(t)=V_{t}\left(R^{*}(t)\right)-V_{t}(t) .
$$

Since a worker is likely to retire as soon as the utility of the option to postpone retirement becomes smaller than the utility of retiring now, retirement probabilities should depend negatively on the option value.

The option value captures the economic incentives created by the pension system and the labor market because the retirement income $\operatorname{YRET} s(R)$ depends on retirement age according to the adjustment factors and on previous labor income by the benefit rules summarized in sections 5.2 and 5.3. The option value is also closely linked to the pension accrual. This is most easily seen in a simple two-period comparison and for $\gamma$ equals 1 . In this crude approximation, a worker of age $R$ in the first period will retire early if

$$
\alpha \cdot W(R)>\mathrm{YLAB}^{\mathrm{NET}}+\alpha \cdot W(R+1),
$$

where $W(t)$ denotes the present discounted value of pension benefits when retiring at age $t$. Using the definition of $\operatorname{TAXR}(R)$, it follows that a worker will retire in the first period if $\operatorname{TAXR}(R)>1 / \alpha$. Hence, according to this crude approximation, the tax rates well above 50 percent exerted by the current public pension system in Germany will lead to early retirement.

We compute the option value for every person in our sample, using the applicable pension regulations and the imputed earning histories. The parameters chosen are a discount rate $\delta$ of 3 percent, a curvature parameter 
$\gamma$ of 1.0, and a relative utility parameter $\alpha$ of 2.8. Additional private pension income is ignored because it represents only a very small proportion of retirement income as described before. Table 5.6 shows the sample averages.

\subsection{Regression Results}

The variable to be explained is old-age labor force status. Because Germany has very few part-time employees, we model only two states-fully in the labor force and fully retired - unlike the competing-risk analysis of Sueyoshi (1989). We use definition I for retired, based on the self-assessed labor force status (see section 5.4.3).

In each of the following regressions, our main explanatory variable is one of the four incentive variables described in the previous section: accrual rate, implicit tax rate, peak value (which is essentially identical to the accrual of SSW), and option value. The other explanatory variables are the usual suspects: an array of socioeconomic variables, such as gender, marital status, wealth (indicator variables of several financial and real-wealth categories), and a self-assessed health measure ranging from 0 for poor to 10 for excellent health. We do not use the legal disability status as a measure of health since this is endogenous to the retirement decision. The desire for early retirement may prompt workers to seek disability status, and frequently the employer helps in this process to alleviate restructuring. Until recently, disability status was granted for labor market reasons without a link to health.

We link the explanatory variables to the dependent variable by a binary probit model. This does some injustice to the panel nature of our data and probably underestimates the true effect (see Börsch-Supan 2001b, who experiments with several specifications of panel probit models with parametrized correlation patterns over time). This more complicated models can be interpreted as partly nonparametric hazard models for multiple spell data, permitting unobserved heterogeneity and state dependence without imposing a functional form on the duration in a given state, while the simple probit model ignores these temporal effects. ${ }^{22} \mathrm{We}$ conducted several randomeffect estimates that correct for some of the intertemporal correlations. The effects of the incentive variables were slightly strengthened, but the results did not change significantly. Note that our estimation sample includes repeated observations of the same person only while this person is employed. Once the person retires, we assume that this is an absorbing state and include only the first observation in retirement. Hence, our dependent variable is in fact the probability to retire, given that the sample person has

22. Flexible-hazard-rate models of retirement have been estimated by Sueyoshi (1989) and Meghir and Whitehouse (1997), and parametric-hazard-rate models for German data have been estimated by Schmidt (1995) and Börsch-Supan and Schmidt (1996). 
worked during the year before, $p_{t}=\operatorname{Prob}($ retired in $t \mid$ worked in $t-1)$. We then compute the survivor function $S(t)$ conditional on working until the beginning of our window period (age fifty-three) as the product of $\left(1-p_{t}\right)$ from age fifty-three to $t$. The probability of choosing a retirement age $a$ is then $p_{a} \cdot S(a)$ and the expected retirement age is $\Sigma p_{a} \cdot S(a) \cdot a$.

Inserting the option value in this type of a regression model is a practical estimation procedure that can be interpreted as a flexible discrete-time duration model explaining the timing of retirement entry. It ignores, however, the structure of the dynamic optimization that underlies the workers decision regarding when to retire. ${ }^{23}$ Nevertheless, previous experimentation has shown that this pragmatic approach generates robust estimates of the average effects of the incentive variables on retirement, although it is likely to fail the individual variation as precisely as the true dynamic optimization model. ${ }^{24}$

Identification of the incentive variables is possible only if we have meaningful variation in these variables. Sources of variation are

- The level of SSW reached at the earliest retirement age, mainly generated by variation in labor force histories;

- The upper threshold for the social security contributions, mainly generated by their changes over time and the different earnings levels;

- Differences in the pension rules between single workers and couples;

- Widely varying age differences between husband and spouse;

- Restricted eligibility of self-employed;

- Restricted eligibility of women with less than fifteen years of service;

- Differences in the pension formula between private-sector employees and civil servants;

- Differences in the ratio between contribution rates and pension benefits across cohorts (younger cohorts have a substantially lower internal rate of return); and

- Several minor rule changes during our the sample period.

We estimated twenty-four different models: We use four different incentive variables as our main regressors (accrual rate, tax rate, option value, and peak value; see section 5.4.6). For each of these incentive variables, we run probit regressions with three age specifications (linear, quadratic, and a full set of age dummies) as well as with and without including SSW. We pool public and private workers, but have separate regressions for males and females.

We first summarize our main results separately for men and women. Tables 5.8 and 5.10 report the goodness of fit, and tables 5.9 and 5.11 the impact of the incentive variables, measured as the change in the probability of

23. The full underlying dynamic programming model has been estimated by Rust and Phelan (1997).

24. See Lumsdaine, Stock, and Wise (1992). 


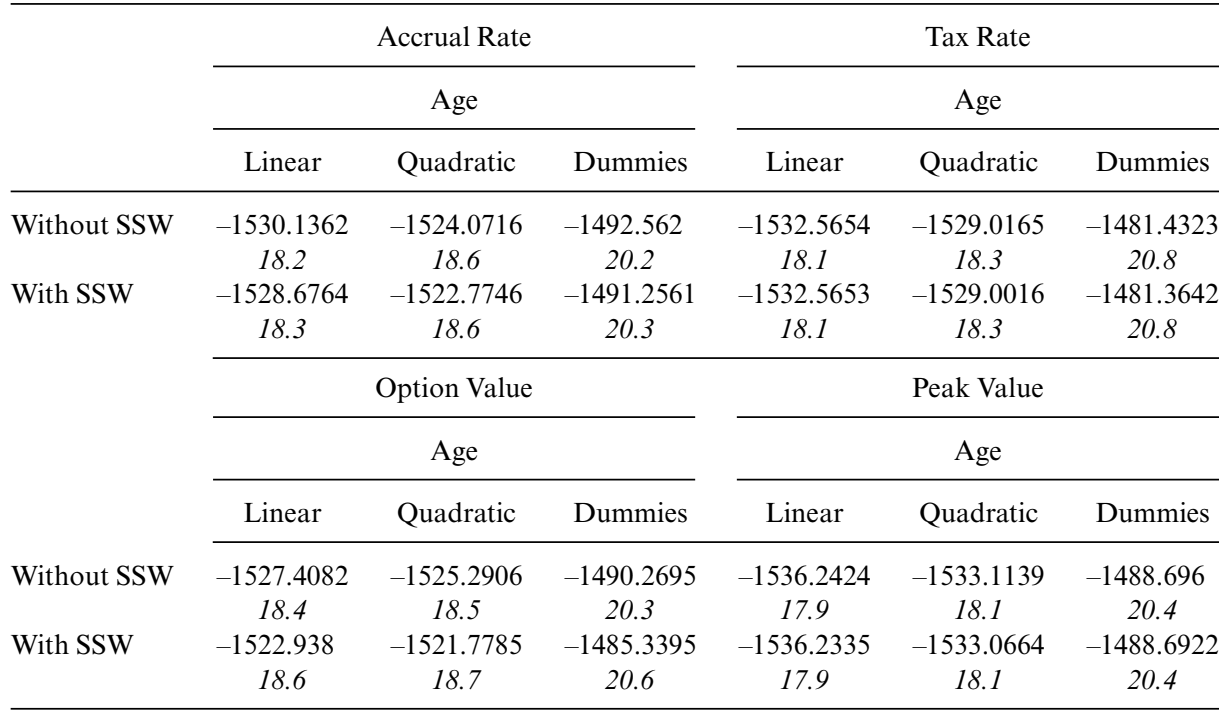

Source: GSOEP, working sample of men, 1984-1997 (available at http://www.diw-berlin.de/gsoep). Note: Percentages in italics are log-likelihood values and pseudo $R^{2}$.

Table 5.9

Marginal Effect of Incentive Variables (males)

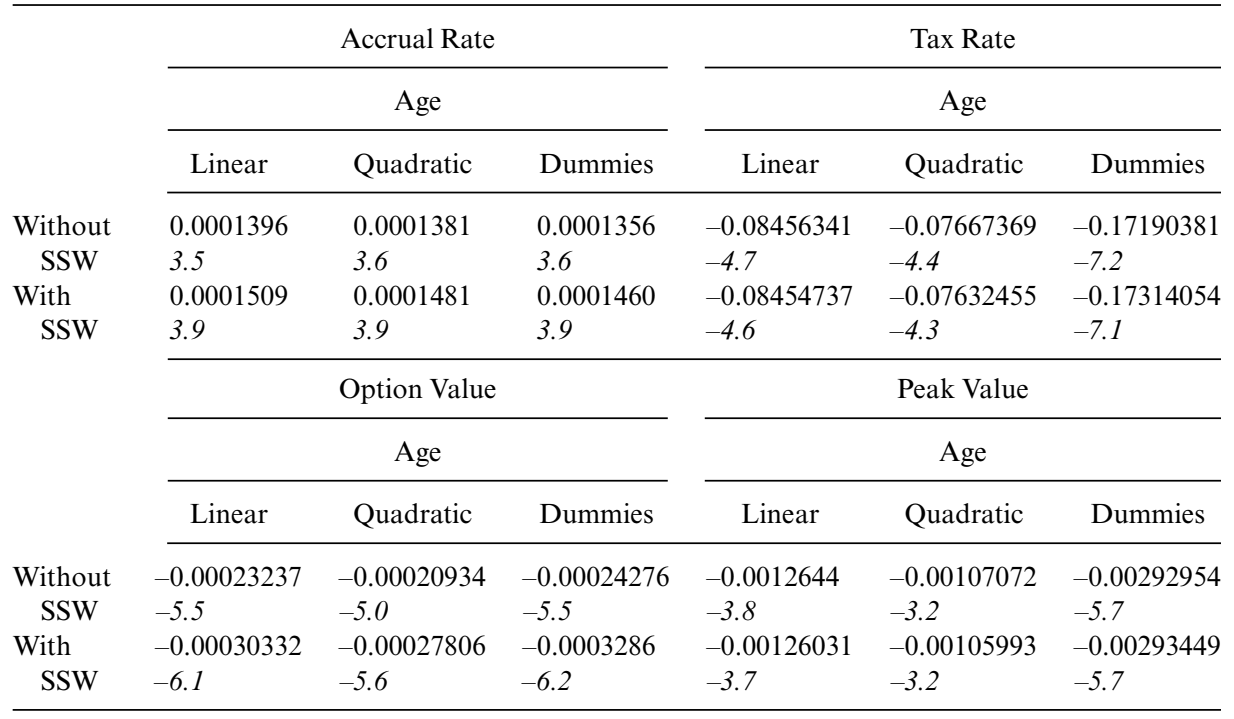

Source: GSOEP, working sample of men, 1984-1997 (available at http://www.diw-berlin.de/gsoep).

Note: Numbers in italics are $\partial P / \partial x$ and $t$-statistics. 


\begin{tabular}{|c|c|c|c|c|c|c|}
\hline & \multicolumn{3}{|c|}{ Accrual Rate } & \multicolumn{3}{|c|}{ Tax Rate } \\
\hline & \multicolumn{3}{|c|}{ Age } & \multicolumn{3}{|c|}{ Age } \\
\hline & Linear & Quadratic & Dummies & Linear & Quadratic & Dummies \\
\hline Without & -691.58206 & -684.4851 & -632.7585 & -687.97887 & -681.87265 & -631.03328 \\
\hline SSW & 18.0 & 18.9 & 24.9 & 18.4 & 19.2 & 25.1 \\
\hline With & -691.28715 & -684.2648 & -632.60559 & -687.95991 & -681.86189 & -631.01395 \\
\hline \multirow[t]{4}{*}{ SSW } & 18.1 & 18.9 & 25.0 & 18.4 & 19.2 & 25.1 \\
\hline & \multicolumn{3}{|c|}{ Option Value } & \multicolumn{3}{|c|}{ Peak Value } \\
\hline & \multicolumn{3}{|c|}{ Age } & \multicolumn{3}{|c|}{ Age } \\
\hline & Linear & Quadratic & Dummies & Linear & Quadratic & Dummies \\
\hline Without & -685.97528 & -679.93327 & -627.72675 & -678.58724 & -672.18414 & -623.80517 \\
\hline SSW & 18.7 & 19.4 & 25.5 & 19.6 & 20.3 & 26.0 \\
\hline With & -684.17131 & -678.30671 & -625.19017 & -677.54142 & -671.08436 & -621.56825 \\
\hline SSW & 18.9 & 19.6 & 25.8 & 19.7 & 20.4 & 26.3 \\
\hline
\end{tabular}

Source: GSOEP, working sample of men, 1984-1997 (available at http://www.diw-berlin.de/gsoep). Note: Percentages in italics are log-likelihood values and pseudo $R^{2}$.

Table 5.11 Marginal Effect of Incentive Variables (females)

\begin{tabular}{|c|c|c|c|c|c|c|}
\hline & & Accrual Rate & & & Tax Rate & \\
\hline & & Age & & & Age & \\
\hline & Linear & Quadratic & Dummies & Linear & Quadratic & Dummies \\
\hline Without & 0.0000087 & 0.0000115 & 0.0000046 & -0.01152618 & -0.01250953 & -0.01550037 \\
\hline SSW & & 0.8 & 0.3 & -2.8 & -2.4 & -1.9 \\
\hline With & 0.0000074 & 0.0000102 & 0.0000037 & -0.01180793 & -0.01278009 & -0.01608508 \\
\hline SSW & 0.6 & 0.7 & 0.2 & -2.7 & -2.3 & -1.8 \\
\hline & & Option Value & & & Peak Value & \\
\hline & & Age & & & Age & \\
\hline & Linear & Quadratic & Dummies & Linear & Quadratic & Dummies \\
\hline Without & -0.00005129 & -0.00006159 & -0.00010106 & -0.00133364 & -0.00159996 & -0.00270272 \\
\hline SSW & -3.4 & -3.1 & -3.1 & -5.1 & -5.0 & -4.2 \\
\hline With & -0.00005499 & -0.00006957 & -0.00013015 & -0.00155703 & -0.00189241 & -0.00384073 \\
\hline SSW & -3.7 & -3.4 & -3.7 & -5.2 & -5.1 & -4.6 \\
\hline
\end{tabular}

Source: GSOEP, working sample of men, 1984-1997 (available at http://www.diw-berlin.de/gsoep). Note: Numbers in italics are $\partial P / \partial x$ and $t$-statistics. 
Table 5.12

Probit Estimates for Male Subsample-Incentive Variable OV

\begin{tabular}{|c|c|c|c|c|c|c|c|}
\hline \multirow[b]{2}{*}{ OPTVAL } & \multirow{2}{*}{$\begin{array}{c}d F / d x \\
-.003053\end{array}$} & \multirow{2}{*}{$\begin{array}{c}\text { SE } \\
.0000485\end{array}$} & \multirow{2}{*}{$\begin{array}{c}z \\
-6.07\end{array}$} & \multirow{2}{*}{$\begin{array}{c}P>|z| \\
0.000\end{array}$} & \multirow{2}{*}{$\begin{array}{c}x \text {-bar } \\
249.725\end{array}$} & \multicolumn{2}{|c|}{$95 \%$ C.I. } \\
\hline & & & & & & -.0004 & -.00021 \\
\hline FSSW & -.0001714 & .0000361 & -4.67 & 0.000 & 316.764 & -.000242 & -.000101 \\
\hline AGEDUM55* & -.0035989 & .0146005 & -0.24 & 0.810 & .137001 & -.032215 & .025018 \\
\hline AGEDUM56* & .0171014 & .0172827 & 1.09 & 0.275 & .133765 & -.016772 & .050975 \\
\hline AGEDUM57* & .0283252 & .0191398 & 1.72 & 0.086 & .123902 & -.009188 & .065838 \\
\hline AGEDUM58* & .03864 & .0213393 & 2.20 & 0.028 & .111111 & -.003184 & .080464 \\
\hline AGEDUM59* & .0422839 & .0230766 & 2.26 & 0.024 & .096933 & -.002945 & .087513 \\
\hline AGEDUM60* & .1134217 & .0357241 & 4.60 & 0.000 & .081368 & .043404 & .18344 \\
\hline AGEDUM61* & .1363814 & .0140872 & 4.97 & 0.000 & .062567 & .055852 & .216911 \\
\hline AGEDUM62* & .112833 & .0408826 & 4.05 & 0.000 & .045307 & .032704 & .192961 \\
\hline AGEDUM63* & .1994108 & .0552118 & 5.69 & 0.000 & .033595 & .091198 & .307624 \\
\hline AGEDUM64* & .4444502 & .0744151 & 8.93 & 0.000 & .022346 & .298599 & .590301 \\
\hline AGEDUM65* & .3689588 & .0861118 & 6.71 & 0.000 & .01125 & .200183 & .537735 \\
\hline AGEDUM66* & .7122481 & .084577 & 8.69 & 0.000 & .006164 & .540834 & .883662 \\
\hline AGEDUM67* & .4784933 & .2128542 & 3.34 & 0.001 & .001079 & .061307 & .89568 \\
\hline AGEDUM68* & .3776805 & .2945118 & 2.03 & 0.042 & .00616 & -.199552 & .954913 \\
\hline AGEDUM71* & .6680958 & .3101597 & 2.53 & 0.012 & .000308 & .060194 & 1.276 \\
\hline HEALTH & -.0101493 & .0009479 & -11.65 & 0.000 & 9.07096 & -.012007 & -.008292 \\
\hline MARRIED* & -.0076327 & .0119856 & -0.68 & 0.498 & .95161 & -.031124 & .015859 \\
\hline UNI* & -.027545 & .007122 & -2.96 & 0.003 & .128833 & -.041504 & -.013586 \\
\hline SKILL & .0029414 & .0058029 & 0.51 & 0.612 & .869934 & -.008432 & .014315 \\
\hline VEIGEN* & .0062658 & .0050534 & 1.24 & 0.216 & .53059 & -.003639 & .01617 \\
\hline VNULL* & -.0050004 & .0078429 & -0.61 & 0.541 & .087225 & -.020372 & .010371 \\
\hline VWP* & .0156084 & .0067196 & 2.51 & 0.012 & .229619 & .002438 & .028779 \\
\hline VPDAUER & .0001696 & .001485 & 0.11 & 0.909 & 38.3005 & -.002741 & .00308 \\
\hline VPDAUER $^{2}$ & $-3.57 \mathrm{e}-06$ & .0000249 & -0.14 & 0.886 & 1521.28 & -.000052 & .000045 \\
\hline YHAT & .0012985 & .0003284 & 3.92 & 0.000 & 59.9149 & .000655 & .001942 \\
\hline YHAT $^{2}$ & $2.80 \mathrm{e}-06$ & $5.51 \mathrm{e}-07$ & 4.95 & 0.000 & 4499.21 & $1.7 \mathrm{e}-06$ & $3.9 \mathrm{e}-06$ \\
\hline$d s^{*}$ & -.022587 & .0057826 & -3.13 & 0.002 & .107104 & -.033921 & -.011253 \\
\hline$d b^{*}$ & .0464132 & .0141686 & 4.14 & 0.000 & .093389 & .018643 & .074183 \\
\hline KIDS* & -.0075237 & .0048206 & -1.55 & 0.122 & .419171 & -.016972 & .001925 \\
\hline Obs. $P$ & \multicolumn{7}{|l|}{.0826013} \\
\hline Pred. $P$ & \multicolumn{7}{|c|}{.0412237 (at $x$-bar) } \\
\hline \multicolumn{8}{|c|}{ No. of obs. $=6,489$} \\
\hline \multicolumn{8}{|c|}{$\operatorname{LR} \chi^{2}(31)=870.62$} \\
\hline \multicolumn{8}{|c|}{ Prob $>\chi^{2}=0.0000$} \\
\hline \multicolumn{8}{|c|}{ Pseudo $R^{2}=0.2353$} \\
\hline \multicolumn{8}{|c|}{ Log-likelihood $=-1414.5558$} \\
\hline
\end{tabular}

Source: GSOEP, working sample of men, 1984-1997 (available at http://www.diw-berlin.de/gsoep). Note: An asterisk denotes dummy variables.

being retired when the incentive variable is changed infinitesimally. Tables 5.12 and 5.13 show full regression results for our favorite specification (option value with SSW and with a full set of age dummies). The other specifications produce very similar results in terms of significance and signs.

Using tax rate and peak value yield significantly better fits than accrual rate and option value in almost all specifications. There is little difference 
Probit Estimates for Female Subsample-Incentive Variable OV

\begin{tabular}{|c|c|c|c|c|c|c|c|}
\hline & $d F / d x$ & SE & $z$ & $P>|z|$ & $x$-bar & \multicolumn{2}{|c|}{$95 \%$ C.I. } \\
\hline OPTVAL & -.0001008 & .0000657 & -3.54 & 0.000 & 157.169 & -.000229 & .000028 \\
\hline FSSW & -.0000474 & .0000351 & -2.13 & 0.033 & 118.39 & -.000116 & .000021 \\
\hline AGEDUM55* & -.000499 & .0044412 & -0.11 & 0.912 & .152008 & -.009204 & .008206 \\
\hline AGEDUM56* & .0009751 & .0049257 & 0.21 & 0.835 & .137986 & -.008679 & .010629 \\
\hline AGEDUM57* & -.0006681 & .0043968 & -0.15 & 0.882 & .12747 & -.009286 & .00795 \\
\hline AGEDUM58* & .0002302 & .0047638 & 0.05 & 0.961 & .114404 & -.009107 & .009567 \\
\hline AGEDUM59* & .0042321 & .0073449 & 0.78 & 0.434 & .100064 & -.010164 & .018628 \\
\hline AGEDUM60* & .0606805 & .0448888 & 4.97 & 0.000 & .079987 & -.0273 & .148661 \\
\hline AGEDUM61* & .1375386 & .0839864 & 6.78 & 0.000 & .051307 & -.027072 & .302149 \\
\hline AGEDUM62* & .0385825 & .0360184 & 2.92 & 0.003 & .028043 & -.032012 & 109177 \\
\hline AGEDUM63* & .0209055 & .0247693 & 1.79 & 0.074 & .02167 & -.027641 & .069241 \\
\hline AGEDUM64* & .0712695 & .0611771 & 3.48 & 0.001 & .015296 & -.048636 & .191174 \\
\hline AGEDUM65* & .2828068 & .1450685 & 6.64 & 0.000 & .011791 & -.001522 & .567136 \\
\hline AGEDUM66* & .4289469 & .2050834 & 5.55 & 0.000 & .004461 & .026991 & .830903 \\
\hline AGEDUM67* & .0305762 & .0538137 & 1.08 & 0.279 & .002231 & -.074897 & .136049 \\
\hline AGEDUM69* & -.0046263 & .0085027 & -0.40 & 0.691 & .001912 & -.021291 & .012039 \\
\hline AGEDUM70* & .010992 & .0402127 & 0.40 & 0.690 & .000956 & -.067823 & .089808 \\
\hline AGEDUM71* & .017278 & .0628126 & 0.44 & 0.662 & .000637 & -.105832 & .140388 \\
\hline HEALTH & -.0018635 & .001441 & -4.52 & 0.000 & 9.42065 & -.004688 & .000961 \\
\hline MARRIED* & -.028244 & .0195633 & -4.46 & 0.000 & .950605 & -.066587 & .010099 \\
\hline UNI* & -.0063273 & .0056794 & -1.53 & 0.126 & .035692 & -.017459 & .004804 \\
\hline SKILL & -.005533 & .004353 & -2.82 & 0.005 & .476099 & -.014065 & .002999 \\
\hline VEIGEN* & -.0005057 & .0019191 & -0.27 & 0.786 & .515934 & -.004267 & .003256 \\
\hline VNULL* & -.0016109 & .0028384 & -0.58 & 0.561 & .108987 & -.007174 & .003952 \\
\hline VWP* & .0013406 & .0026261 & 0.56 & 0.575 & .202996 & -.003806 & .006488 \\
\hline VPDAUER & .0001974 & .0003477 & 0.67 & 0.504 & 20.1118 & -.000484 & .000879 \\
\hline VPDAUER $^{2}$ & $-3.72 \mathrm{e}-06$ & $6.74 \mathrm{e}-06$ & -0.63 & 0.529 & 558.3 & -.000017 & $9.5 \mathrm{e}-06$ \\
\hline YHAT & .0009701 & .0005632 & 3.97 & 0.000 & 28.7974 & -.000134 & .002074 \\
\hline YHAT $^{2}$ & $-2.41 \mathrm{e}-06$ & $6.26 \mathrm{e}-07$ & -2.02 & 0.043 & 6598 & $-3.6 \mathrm{e}-06$ & $-1.2 \mathrm{e}-06$ \\
\hline$d s^{*}$ & -.006747 & .0053123 & -2.66 & 0.008 & .089229 & -.016887 & .003937 \\
\hline$d b^{*}$ & .0410058 & .0534307 & 1.63 & 0.103 & .007967 & -.063716 & .145728 \\
\hline KIDS* & .0007423 & .0021086 & 0.36 & 0.717 & .345124 & -.00339 & .004875 \\
\hline Obs. $P$ & .0761632 & & & & & & \\
\hline Pred. $P$ & .0080778 & $x$-bar) & & & & & \\
\hline No. of obs. $=3$, & & & & & & & \\
\hline $\operatorname{LR} \chi^{2}(31)=46$ & & & & & & & \\
\hline Prob $>\chi^{2}=0.0$ & & & & & & & \\
\hline Pseudo $R^{2}=0.2$ & & & & & & & \\
\hline Log-likelihood & -613.60367 & & & & & & \\
\hline
\end{tabular}

Source: GSOEP, working sample of men, 1984-1997 (available at http://www.diw-berlin.de/gsoep). Note: An asterisk denotes dummy variables.

between including SSW or not, although introducing age dummies makes a large difference. Judging from the goodness of fit, the regression with age dummies but without SSW, is our favorite specification. The pseudo $R^{2}$ is just about 20 percent, a satisfactory but not excellent value.

All incentive variables have the correct sign and are highly significant. 
They are very robust across all the different specifications, including inclusion of other covariates, sample selection, and definition of retirement (not shown in table). Including age dummies yields larger marginal effects and better precision, while including SSW has a very small weakening effect.

The estimation sample also includes civil servants. We have programmed the incentive variables for civil servants using the pension rules for civil servants, which should lead to stronger incentives for early retirement. However, estimates for a sample of civil servants only are disappointing. The most probable reason is that we do not capture the incentives created by promotion possibilities, the main reason for civil servants to retire later than measured by our incentive variables.

Turning to the female sample, results are much weaker than for males. While the overall fit is comparable and sometimes even better, the incentive variables are very weak. Only option value and peak value are significant, with one incorrect sign for peak value in the specification with SSW and linear age. Table 5.12 shows the full regression results for our favorite specification in the full sample.

The incentive variable (here, option value) is highly significant as pointed out before. The set of age dummies is also highly significant and elevates the probabilities to retire after ages sixty, sixty-three, and sixtyfive, the earliest retirement ages under the various pathways (see table 5.1). There clearly is an independent effect of age and the incentive variable on retirement. Self-reported health is also highly significant: Healthier workers retire substantially later than those males who report poor health. Married males do not have a different retirement behavior than single males. However, if there is (still) a child in the household retirement is more likely to be deferred. The effect of a college degree on retirement age is very strong and is present although we have an income measure (yhat and yhat ${ }^{2}$ ) as an additional control. The wealth variables indicate that there is a wealth effect, also weak and barely significant: Persons with higher wealth (indicated by homeownership and financial assets) can afford an earlier retirement. Also, higher labor income weakens labor force attachment. Note that the higher opportunity costs of retirement have already been accounted for in the option value variable, and hence, this income effect is over and above this plus the wealth effect. Two dummy variables indicate the former labor force status. These variables take the value of 1 if the person is actually or used to be a self-employed or a civil servant. The model indicates that the self-employed tend to work longer, while civil servants retire earlier. Both result confirm our expectations.

The peaks of the age dummies are now much more pronounced at age sixty and sixty-five, in accordance with the different rules for women. Most socioeconomic variables have similar (but weaker) effects compared with the male sample. Different, however, is the effect of being married: Married women retire later, probably because they have raised children and there- 
fore have an interrupted earnings record such that they are not yet eligible for retirement at age sixty.

\subsection{Simulation Results}

We now apply the estimated coefficients to several simulation experiments. We first simulate reforms that are close to what happened in Germany in the 1992 reform and what the next reform step may strengthen: shifting the retirement age up by making the system more actuarially fair. Second, we simulate several reforms not specific to Germany and unlikely to happen, but which are used to compare the retirement incentive effects across the countries represented in this volume.

\subsubsection{Reform Options Specific to Germany}

The first country-specific experiment shows what is likely to happen when the 1992 reform is fully phased in. The experiment applies the adjustment factors for early retirement that have been introduced by the pension reform 1992 (3.6 percent per year of early retirement) and compares it to the previous situation without any explicit adjustments. The 1992 adjustment factors have been phased in after our sample period and will take full force from the year 2004 onward. They are not actuarial fair, and they are not effective before age sixty because they are overruled by the special earnings-point credits given under disability insurance.

The second country-specific experiment goes one step further and introduces a geometric adjustment of 6 percent per year that comes closer to a actuarially fair adjustment. The experiment can therefore be thought of as a preview of a potential pension reform after the 2002 elections. It is applied to all ages in the window period (ages fifty-four to sixty-nine), anchored at the pivotal retirement age of sixty-five.

For each policy scenario we use the estimated parameter values in order to compute the probability to retire at age $x$ given that the worker has worked until age fifty-three. We first display the baseline probabilities (i.e., predicted under the pension rules of 1972 valid in our sample period). We then predicted probabilities under the hypothetical new rules (see figures 5.5 and 5.6 based on a specification with age and age squared, rather than linear age or a set of age dummies). The figures show the shift to the right of the distribution, resulting in an increase of the average retirement age.

This resulting increase in retirement age is displayed in table 5.14. It amounts to eight months for the 1992 reform, and seventeen months for a system that is almost actuarially fair. Given that the average retirement age is about sixty years in 1999 for German males, the adjustment factor of 6 percent would imply an increase of the retirement age to sixty-one-andone-half years for males. The impact of such a reform on the budget of the PAYG system would be considerable. Given that the average duration of 


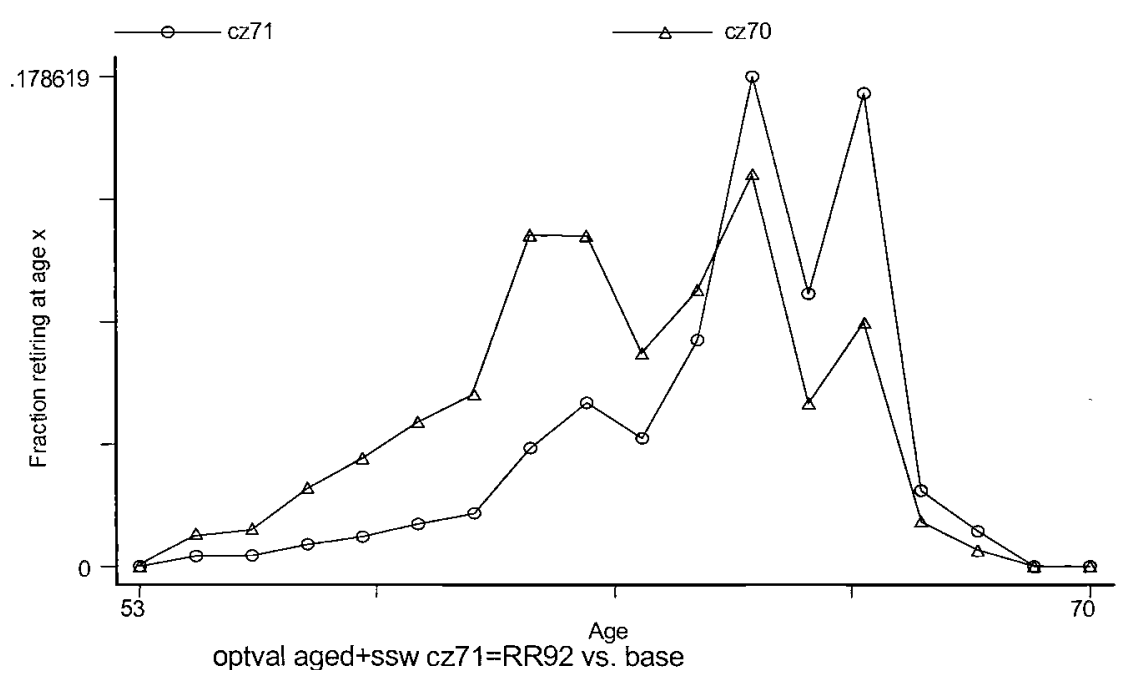

Fig. 5.5 Baseline and predicted distribution of retirement ages (1992 reform)

Source: GSOEP, working sample of males, 1984-1997 (available at http://www.diw-berlin.de/ gsoep).

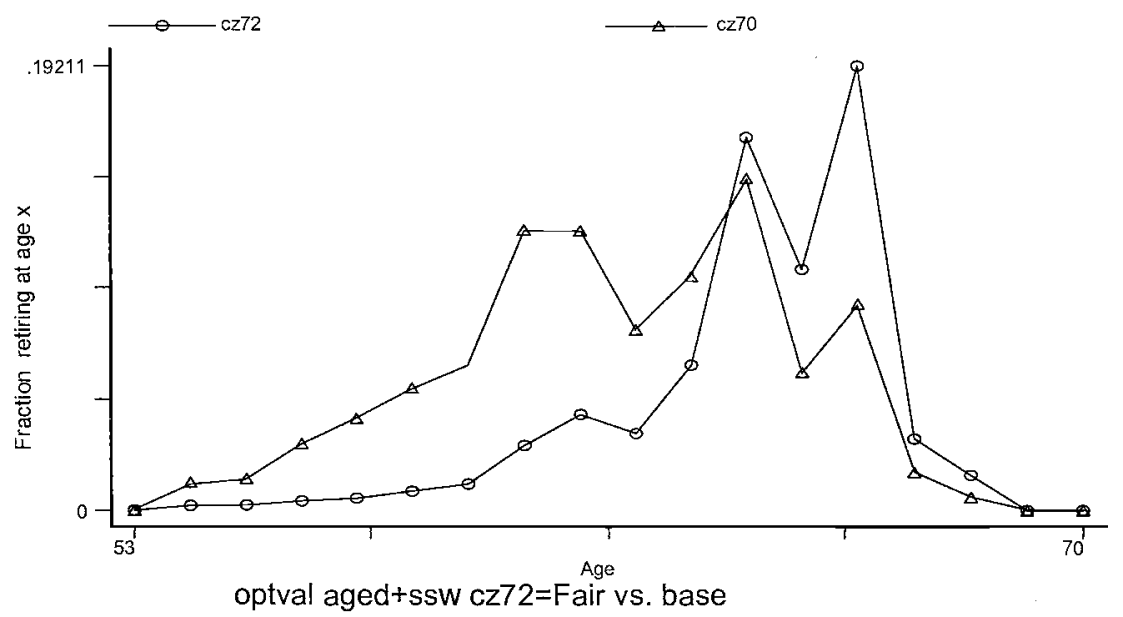

Fig. 5.6 Baseline and predicted distribution of retirement ages (fair system)

Source: GSOEP, working sample of males, 1984-1997 (available at http://www.diw-berlin.de/ gsoep).

pension receipts was sixteen years prior to the reform, expenditure would decrease by roughly 10 percent through this effect. A second effect works through the extended working life, which leads to higher contributions. Two additional years, relative to forty service years, increase the contributions to the PAYG system by 5 percent — provided that deferred take-up of 
Effects of Policy Reforms on Expected Retirement Age

\begin{tabular}{|c|c|c|c|c|c|c|}
\hline & \multicolumn{3}{|c|}{ With SSW } & \multicolumn{3}{|c|}{ Without SSW } \\
\hline & \multicolumn{3}{|c|}{ Age } & \multicolumn{3}{|c|}{ Age } \\
\hline & Linear & Quadratic & Dummies & Linear & Quadratic & Dummies \\
\hline \multicolumn{7}{|c|}{ Simulation A (1992 Reform), Men } \\
\hline Accrual rate & -0.10 & -0.10 & -0.09 & 0.41 & 0.34 & 0.72 \\
\hline Tax rate & -0.12 & -0.12 & -0.11 & 0.41 & 0.34 & 0.73 \\
\hline Option value & 1.90 & 1.74 & 1.55 & 0.39 & 0.32 & 0.73 \\
\hline Peak value & 2.31 & 2.16 & 1.86 & 0.39 & 0.31 & 0.73 \\
\hline \multicolumn{7}{|c|}{ Simulation B (6\% Geometric Adjustment Factors), Men } \\
\hline Accrual rate & -0.10 & -0.10 & -0.09 & 0.91 & 0.79 & 1.57 \\
\hline Tax rate & -0.12 & -0.12 & -0.11 & 0.91 & 0.79 & 1.58 \\
\hline Option value & 2.63 & 2.45 & 2.12 & 1.11 & 0.93 & 1.85 \\
\hline Peak value & 3.06 & 2.91 & 2.39 & 1.11 & 0.93 & 1.85 \\
\hline \multicolumn{7}{|c|}{ Simulation A (1992 Reform), Women } \\
\hline Accrual rate & -0.02 & -0.02 & -0.01 & 0.12 & 0.08 & 0.08 \\
\hline Tax rate & -0.02 & -0.02 & 0.00 & 0.12 & 0.08 & 0.09 \\
\hline Option value & 1.01 & 0.89 & 0.77 & 0.42 & 0.26 & 0.40 \\
\hline Peak value & 1.42 & 1.28 & 1.18 & 0.46 & 0.27 & 0.52 \\
\hline \multicolumn{7}{|c|}{ Simulation B (6\% Geometric Adjustment Factors), Women } \\
\hline Accrual rate & -0.02 & -0.02 & -0.01 & 0.33 & 0.25 & 0.19 \\
\hline Tax rate & -0.02 & -0.02 & 0.00 & 0.34 & 0.26 & 0.20 \\
\hline Option value & 1.48 & 1.32 & 1.14 & 1.32 & 1.05 & 1.13 \\
\hline Peak value & 1.98 & 1.80 & 1.62 & 1.41 & 1.10 & 1.36 \\
\hline
\end{tabular}

Source: GSOEP, working sample of men, 1984-1997 (available at http://www.diw-berlin.de/ gsoep).

pensions implies additional employment. Moreover, there is a third budgetary effect (compared to the no-reform case) since pension benefits are now lower for all who retire early. This would save another 18 percent.

\subsubsection{Simulations for Cross-National Comparisons}

This second set of simulations serves as a vehicle for an extensive crossnational comparison of the effects that the early retirement incentives exert on retirement behavior. We use two hypothetical reform scenarios (the "three-year-shift reform" and the "common reform," later explained in more detail) and apply them systematically to several variants of our estimated models of retirement. These variants include the option value and the peak value model, each of which is estimated using a linear and a dummy-variable age specification. In the latter case and in combination with the three-year-shift reform, we introduce yet another two variants: one for keeping the dummy variables at their original ages and one for shifting them along with the shift in the incentive variables. These latter variants are designed to bracket possible behavioral effects that are embedded in the 
age dummies; for a particular example, the habitual effects associated with age sixty-five as a psychological anchor for retirement decisions.

The three-year-shift reform increases the ages of early and normal retirement by three years (and the corresponding adjustment factors, if applicable) from the current age in the countries represented by this study. The common reform changes all national systems to a common system with an early retirement age of sixty years, a normal retirement age of sixty-five years, a 60 percent replacement rate at age sixty-five, and a 6 percent per year actuarial adjustment, pivoted at age sixty-five.

In the following set of figures, we show all our results both in terms of hazard rates (left-side panels) and the cumulative distribution function (inverse survival function, right-side panels). For convenience, the hazard rates are also tabulated in the appendix. We summarize our results in table 5.15 which displays the expected average retirement ages for all simulations.

Figure 5.7 shows the fit of the option versus the peak value model used

Table 5.15

Expected Retirement Age

\begin{tabular}{|c|c|c|}
\hline & Men & Women \\
\hline \multicolumn{3}{|c|}{ Sample } \\
\hline Sample frequencies & 61.77 & 61.89 \\
\hline \multicolumn{3}{|c|}{ Base Simulation } \\
\hline \multicolumn{3}{|c|}{ Option value model } \\
\hline Linear age & 62.01 & 62.02 \\
\hline Dummies & 61.79 & 61.89 \\
\hline \multicolumn{3}{|l|}{ Peak value model } \\
\hline Linear age & 62.01 & 62.02 \\
\hline Dummies & 61.79 & 61.90 \\
\hline \multicolumn{3}{|c|}{ Three-Year-Shift Simulation } \\
\hline \multicolumn{3}{|c|}{ Option value model } \\
\hline Linear age & 63.52 & 64.50 \\
\hline Dummies fixed & 63.55 & 64.21 \\
\hline Dummies shifted & 65.52 & 66.23 \\
\hline \multicolumn{3}{|l|}{ Peak value model } \\
\hline Linear age & 62.65 & 62.34 \\
\hline Dummies fixed & 62.46 & 62.55 \\
\hline Dummies shifted & 65.04 & 65.16 \\
\hline \multicolumn{3}{|c|}{ Common Reform Simulation } \\
\hline \multicolumn{3}{|c|}{ Option value model } \\
\hline Linear age & 64.31 & 62.64 \\
\hline Dummies fixed & 64.17 & 62.60 \\
\hline Dummies changed & 63.55 & 64.21 \\
\hline \multicolumn{3}{|l|}{ Peak value model } \\
\hline Linear age & 63.56 & 62.32 \\
\hline Dummies fixed & 63.30 & 62.51 \\
\hline Dummies changed & 62.46 & 62.55 \\
\hline
\end{tabular}

Note: Expected value is taken over distribution truncated at age 69. 

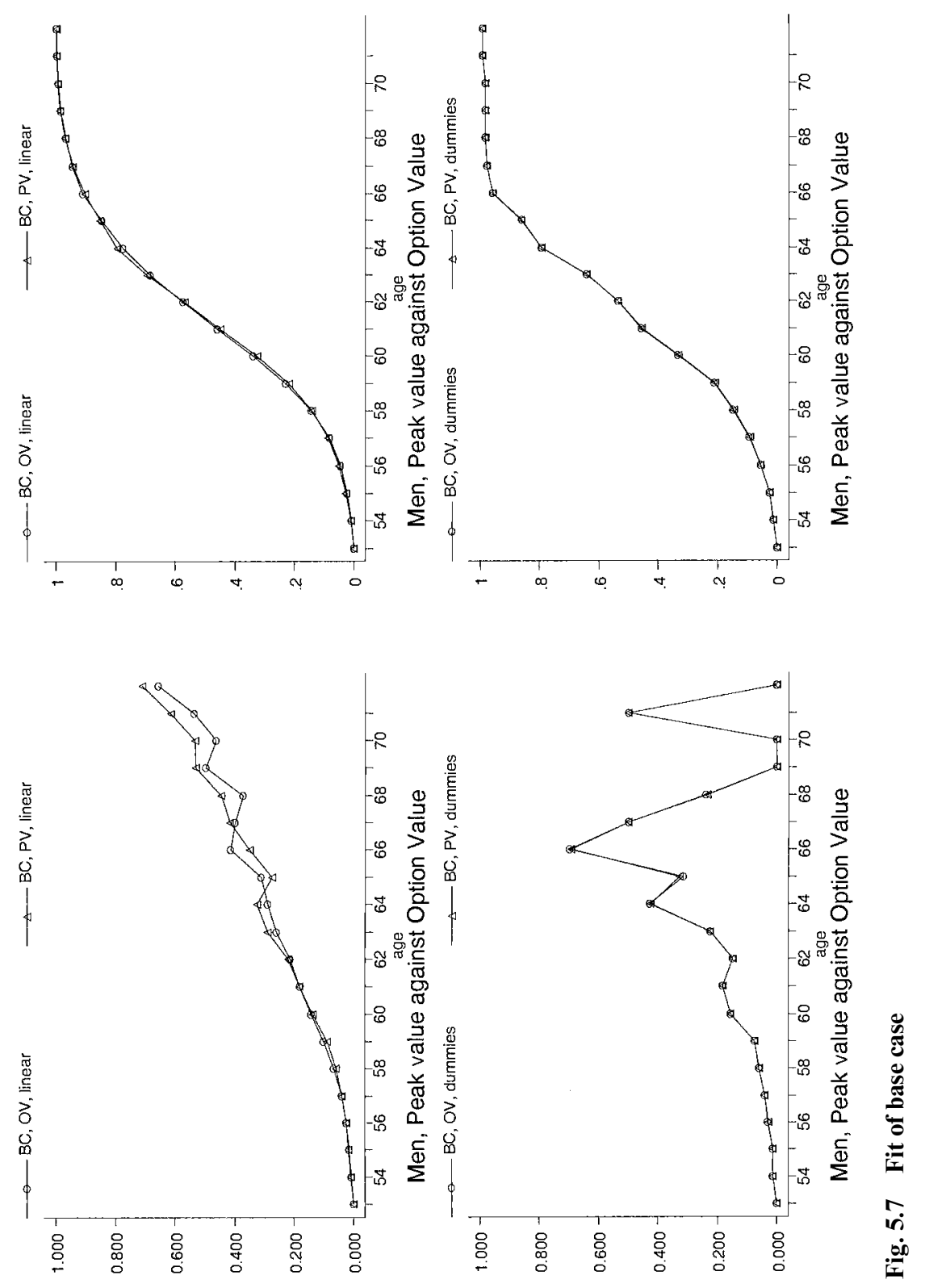

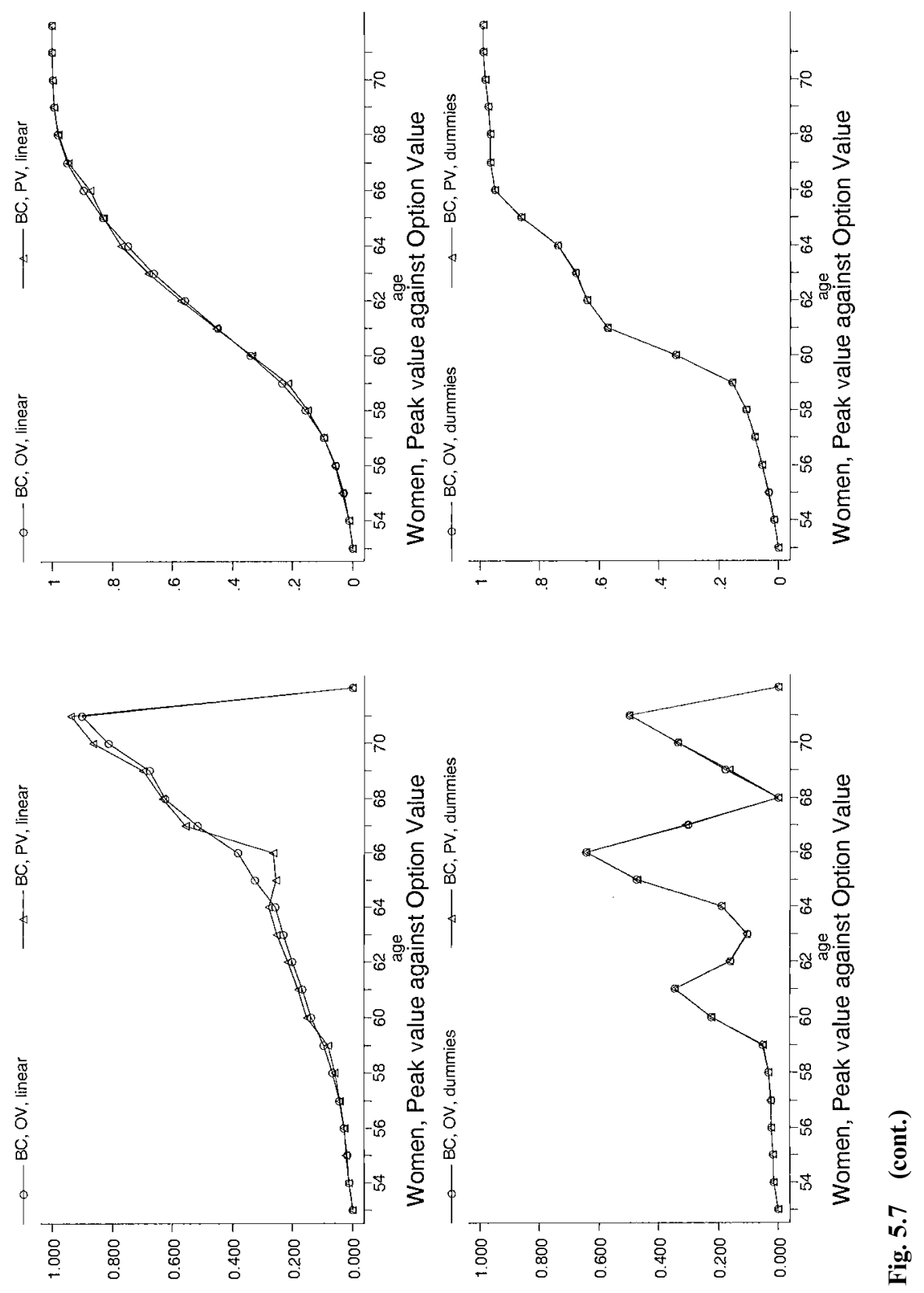
in these simulations. With a linear age specification, the peak value model slightly underestimates retirement at age sixty-five, but in the other ages the two models are very close. They deliver, of course, identical simulations with a full set of dummy variables for each age since in this case the model is fully saturated. Table 5.15 shows the variation among the four models in terms of expected retirement age and how closely the match the actual retirement age.

Figure 5.8 summarizes all simulations. Focusing on the cumulative retirement function, the three-year-shift reform is much more incisive for German men than the common reform, since the common reform keeps the current early retirement age as well as the normal retirement age unchanged. The common reform lowers the replacement rate from currently around 70 percent by 10 percentage points. This actually has very little effects on retirement age. The shift seen in figure 5.8 is mainly an effect of changing the actuarial adjustments and therefore closely corresponds to what we have seen in simulation B in the previous subsection. The effects are more complicated for women. Women have an earlier retirement age (sixty rather than sixty-three), so that the common reform has an even larger effect on women than on men. However, the early retirement age applies only to women with thirty-five years of service. For women with an interrupted work history, the reform has little effect at all because they are restricted to enter retirement at age sixty-five anyway.

Figure 5.8 also shows that the option value model generally predicts larger effects than the peak value model. This difference is isolated in figure 5.9. As seen by the hazard rates, the option value model has a more subtle pattern of peaks than the peak value model, which does not really capture the in-between-peak at age sixty-three.

Another eye-catching difference in figure 5.8 stems from the impact of shifting the dummies as an approximation of the effect, by which all agespecific behavior is shifted by three years. Figure 5.10 isolated these differences for the three-year-shift reform and shows that this makes a huge difference-by about two years concerning the expected retirement age. While these two years are probably an exaggeration of the long-run impact of a later retirement age, the short-run impact measured by keeping the dummies in place is probably an underestimate.

We finish this paper by summarizing that a reform policy of changing the actuarial adjustments, the early retirement ages, or both can indeed shift the retirement age quite substantially. Considering the overall length of retirement (which is currently about seventeen years in Germany), the orders of magnitude - about two years for a set of feasible reform options-is quite significant. 


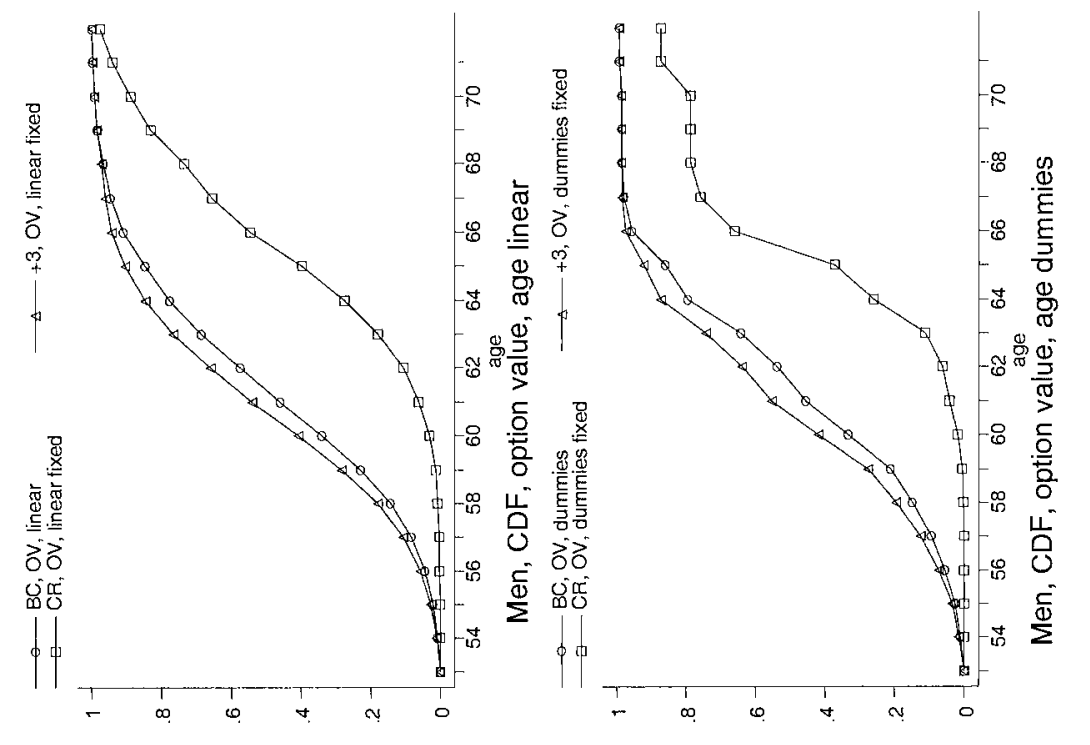

苛
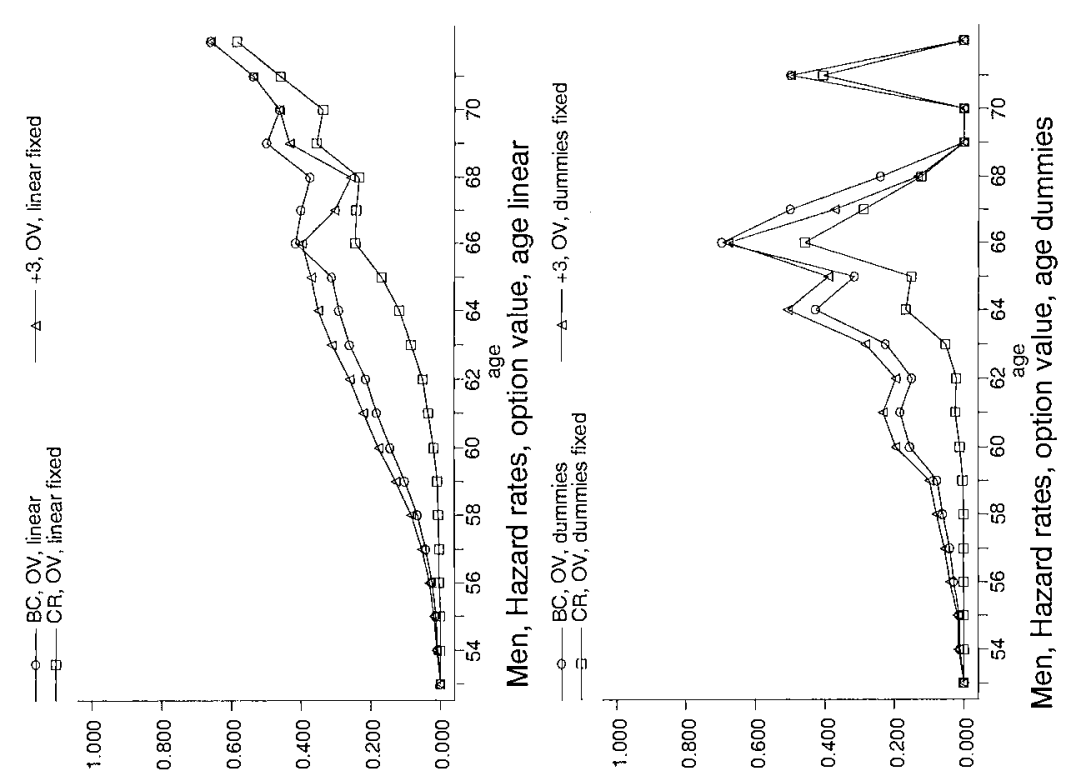

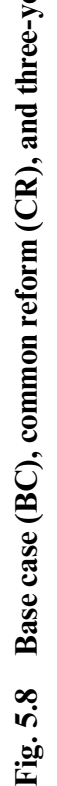



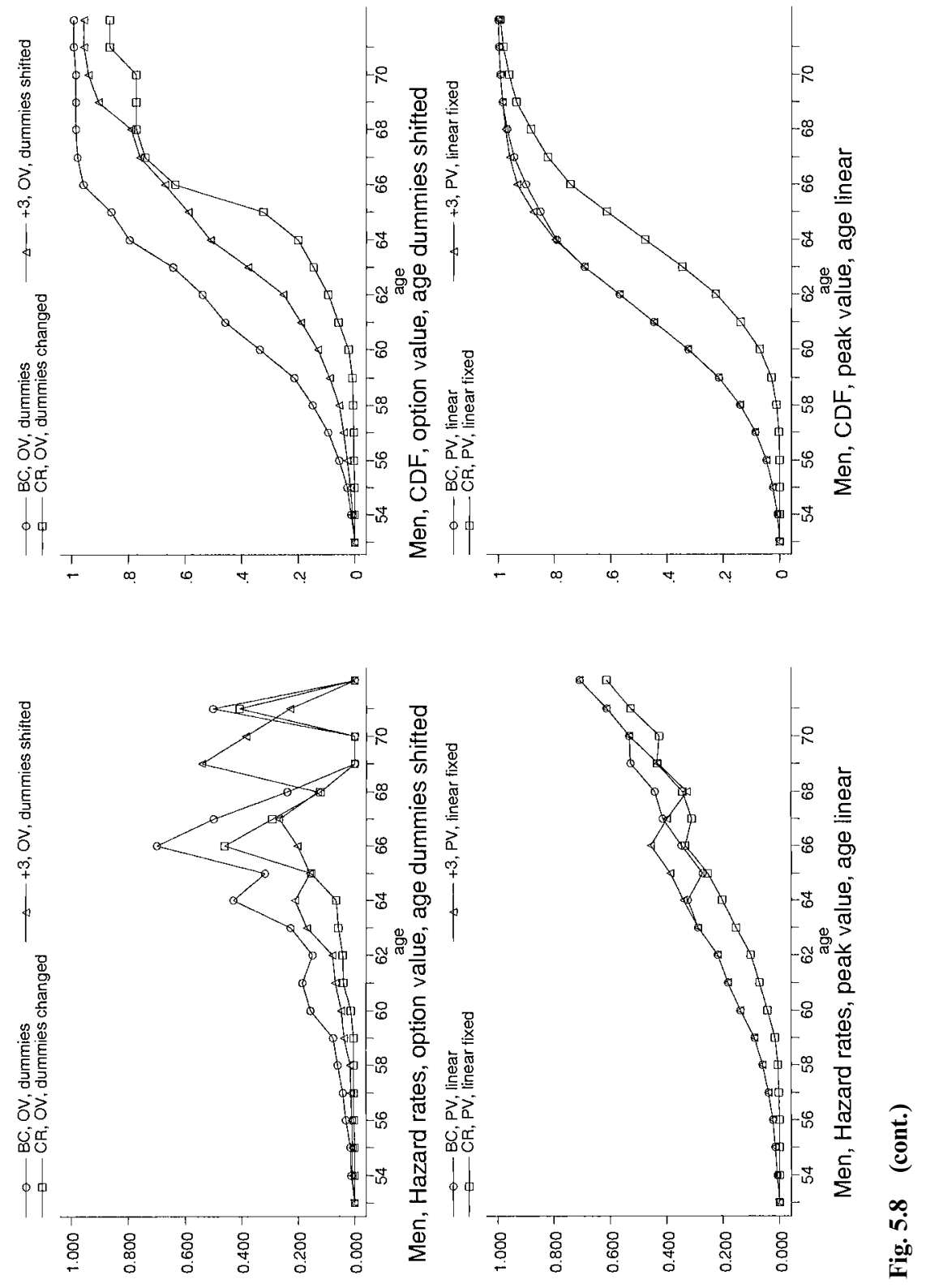

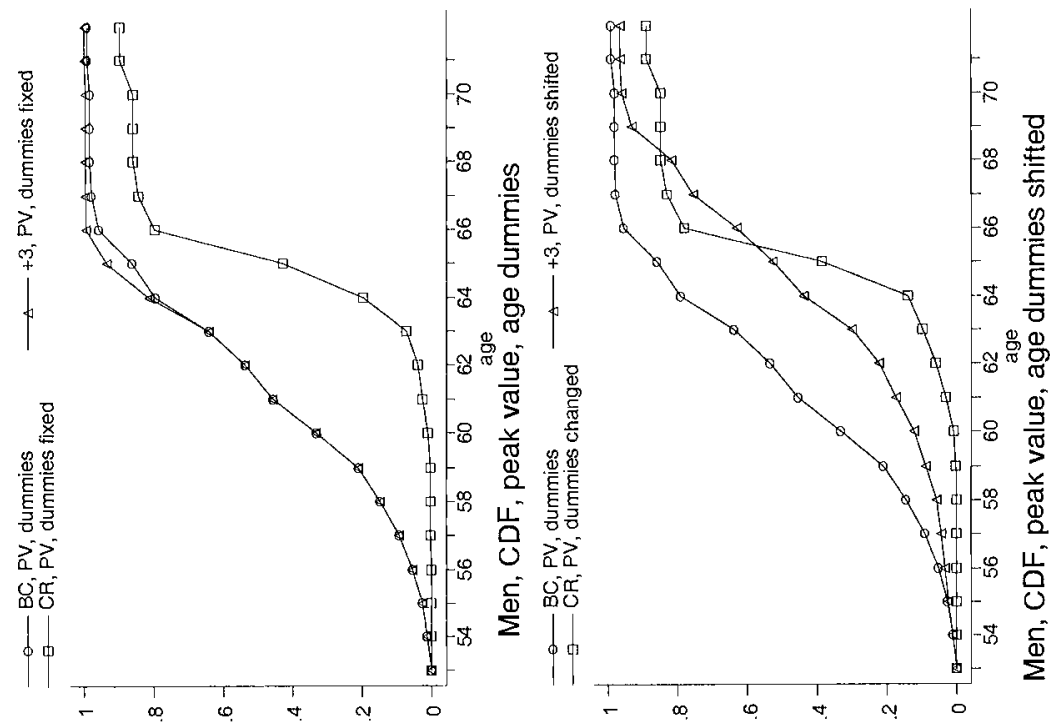

ก
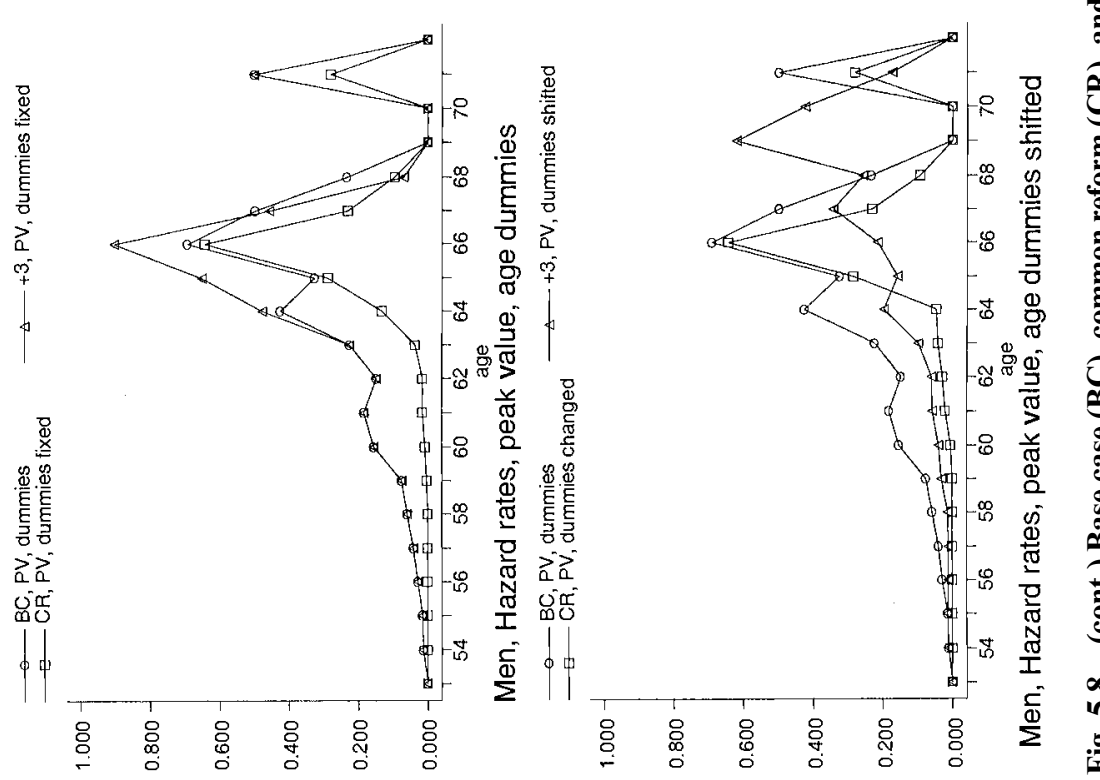

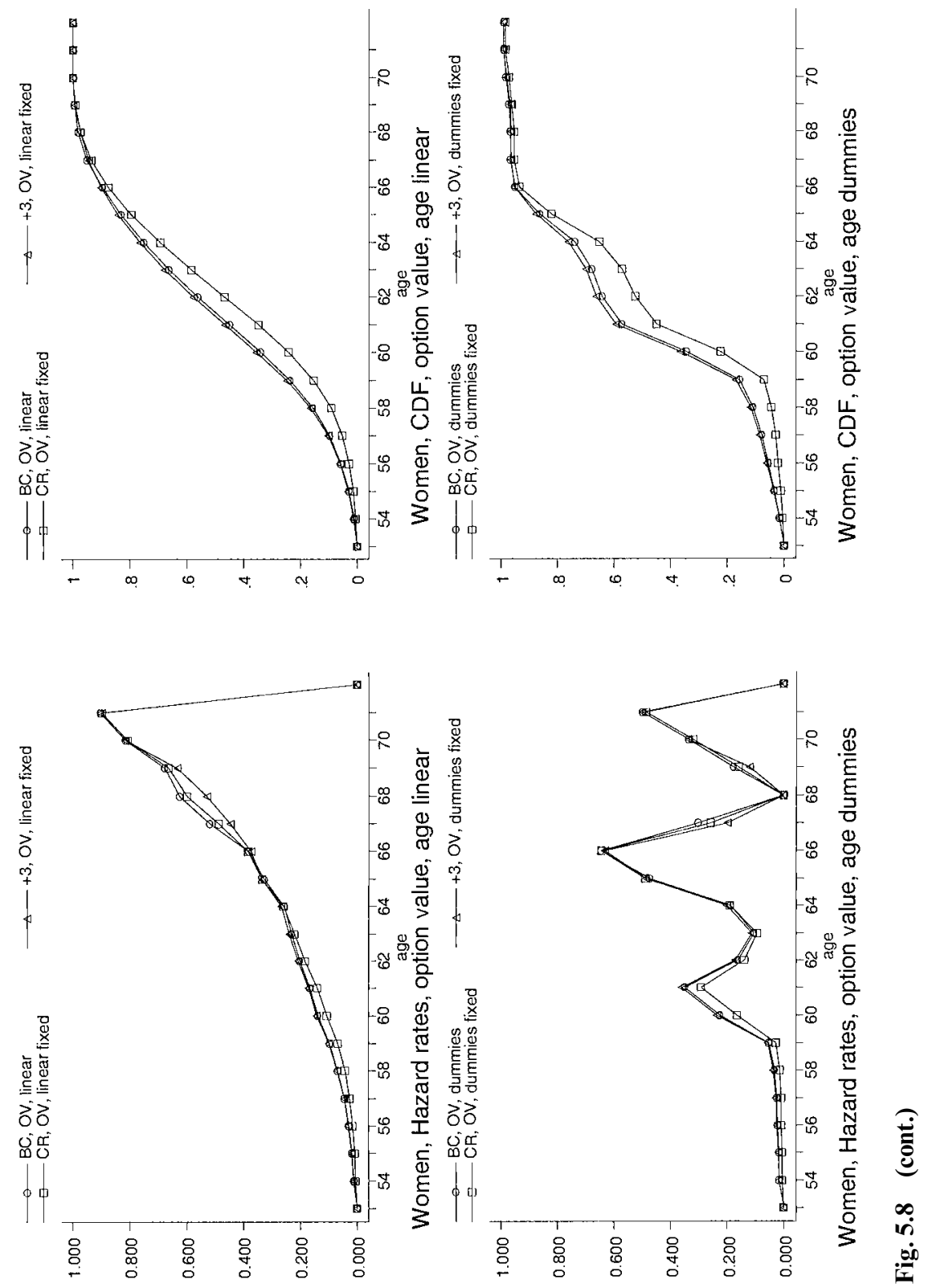


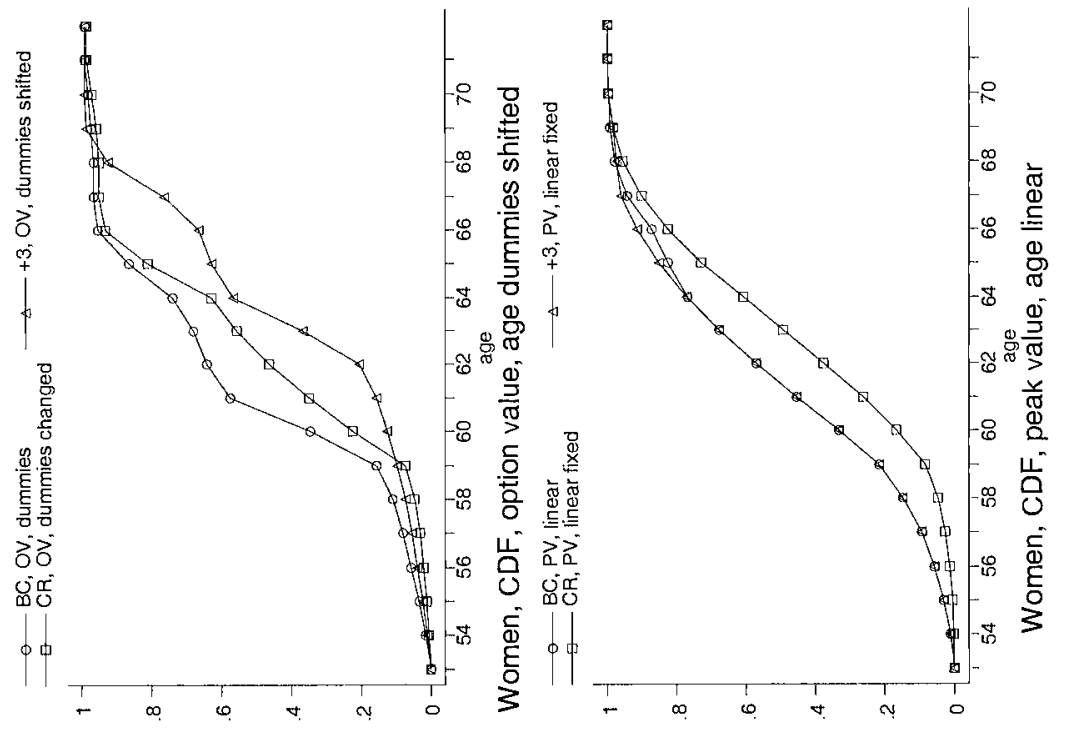

กิ

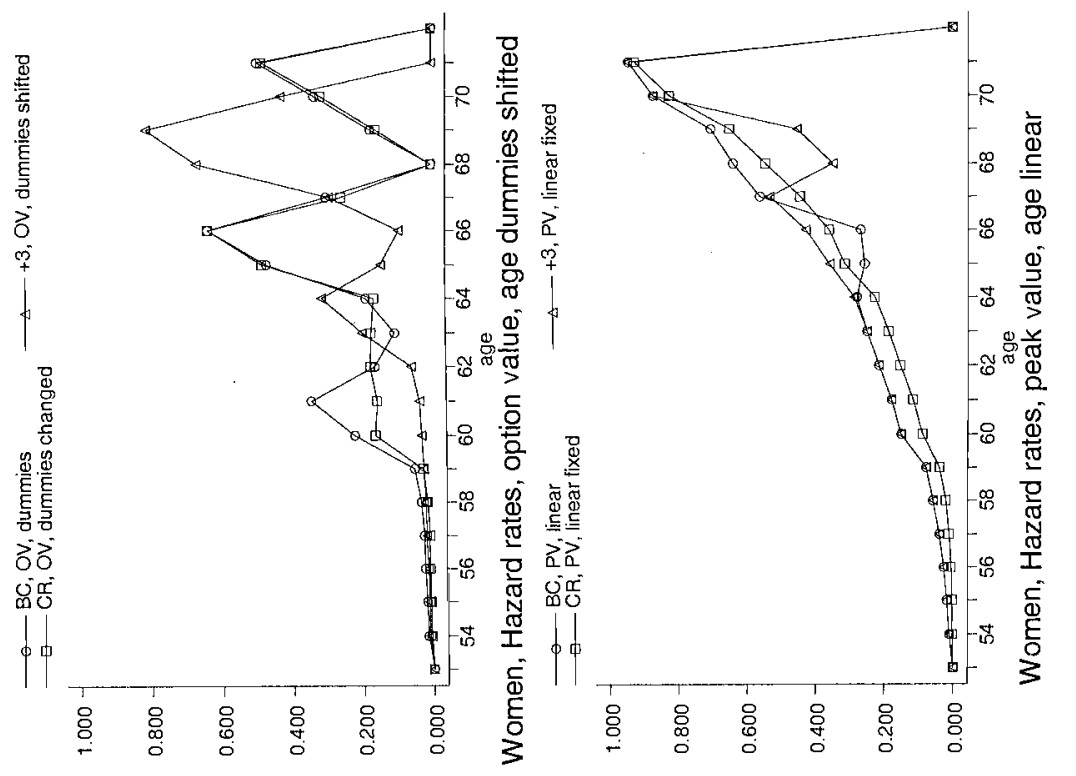



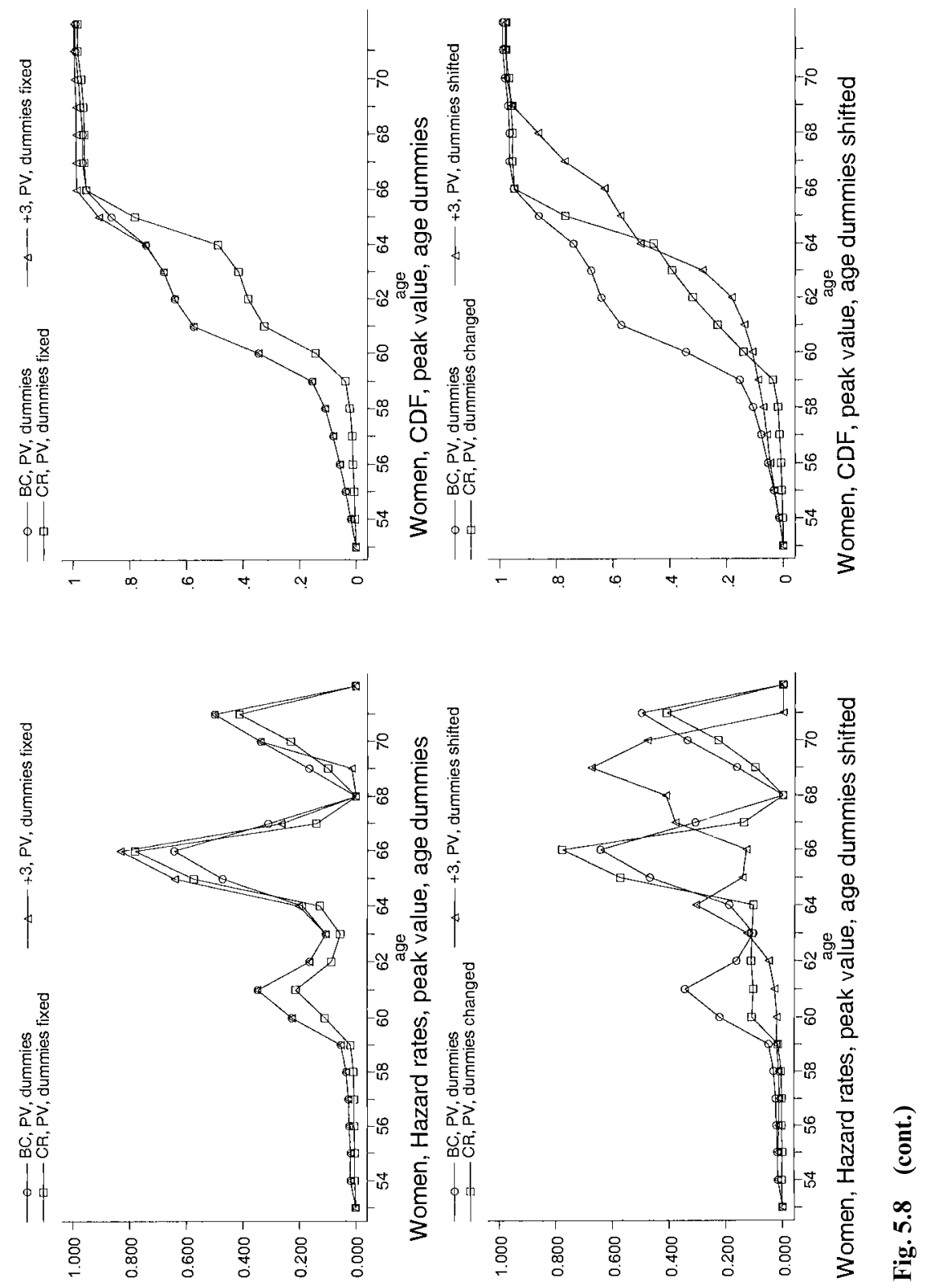

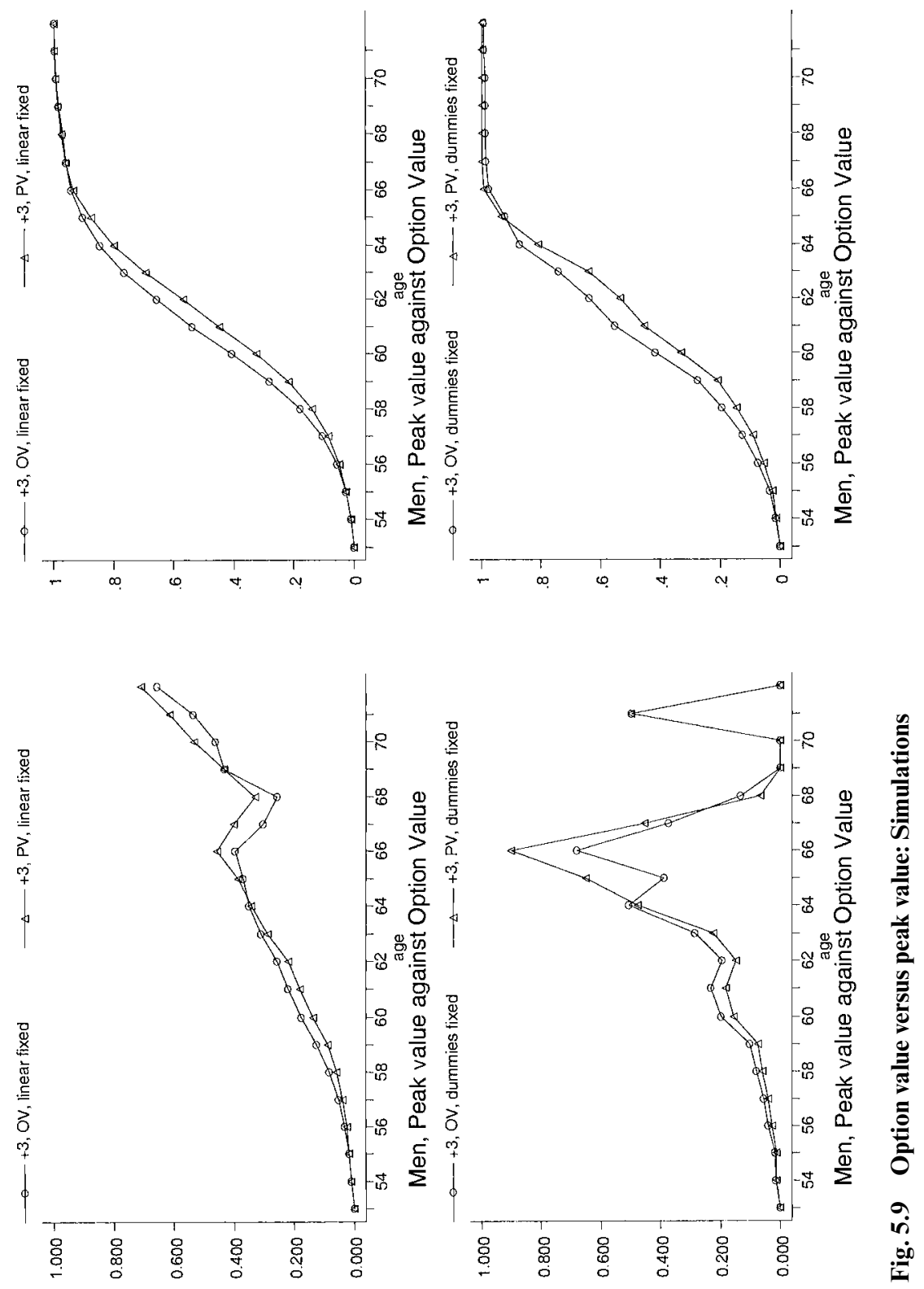

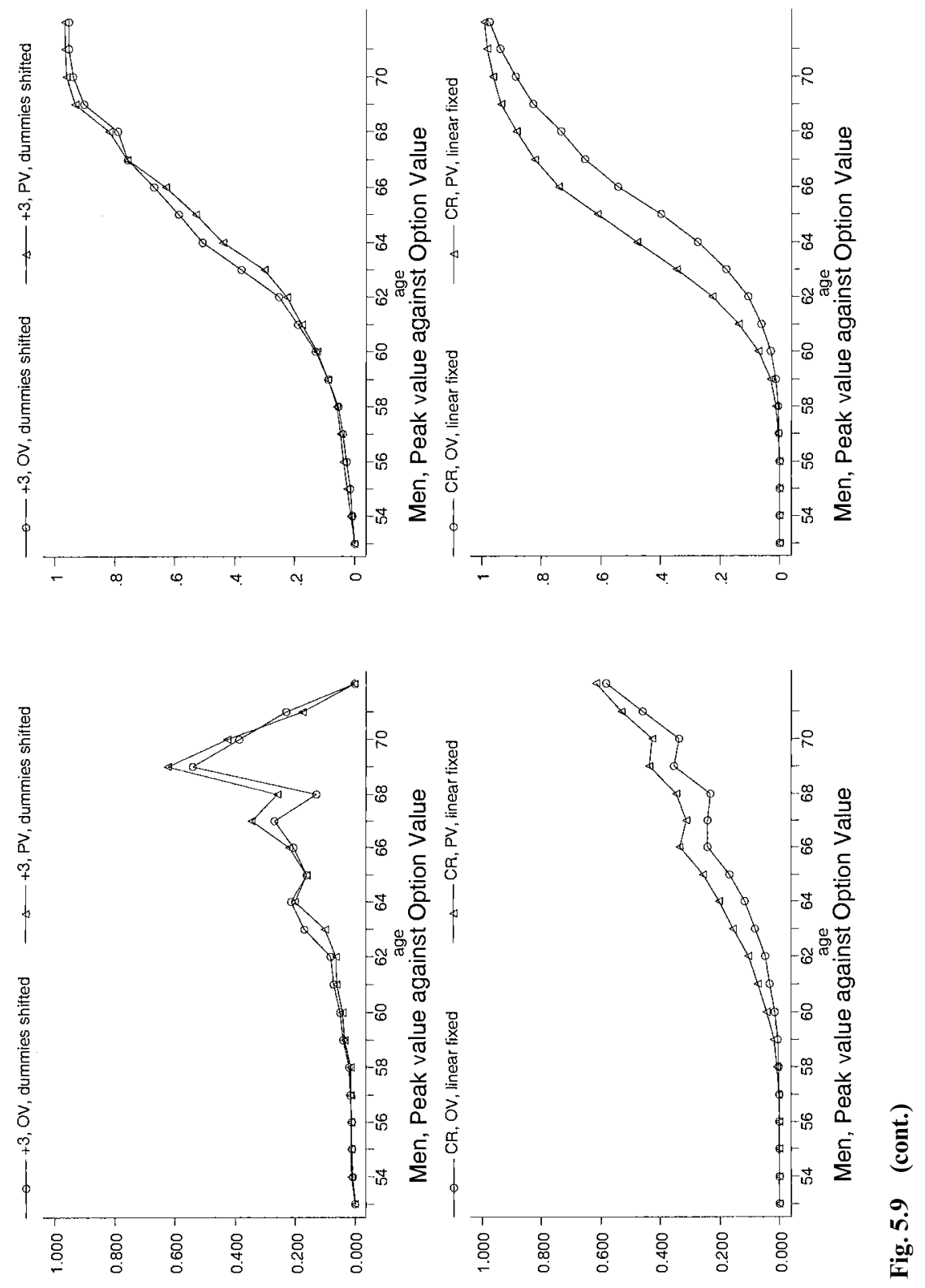

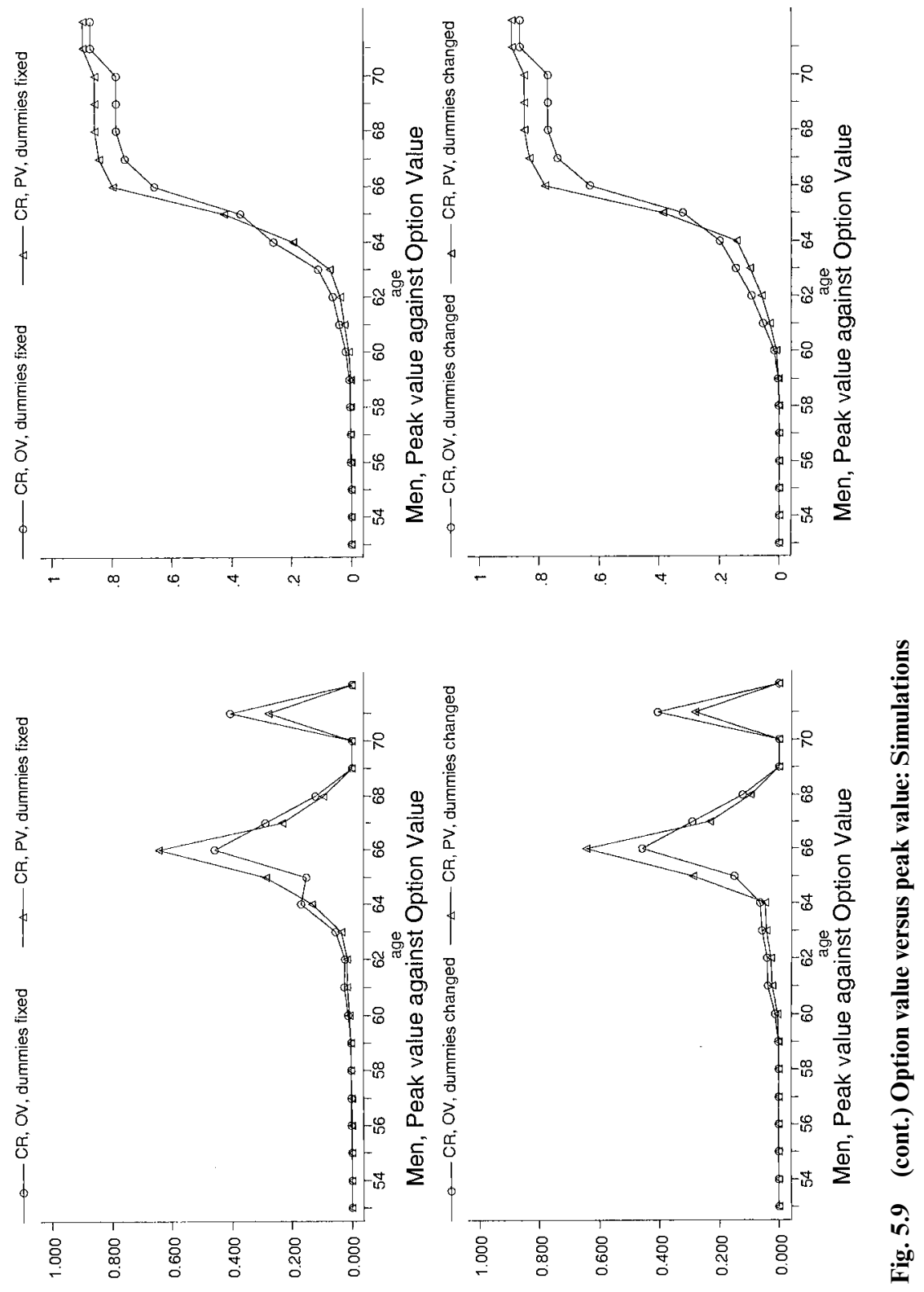

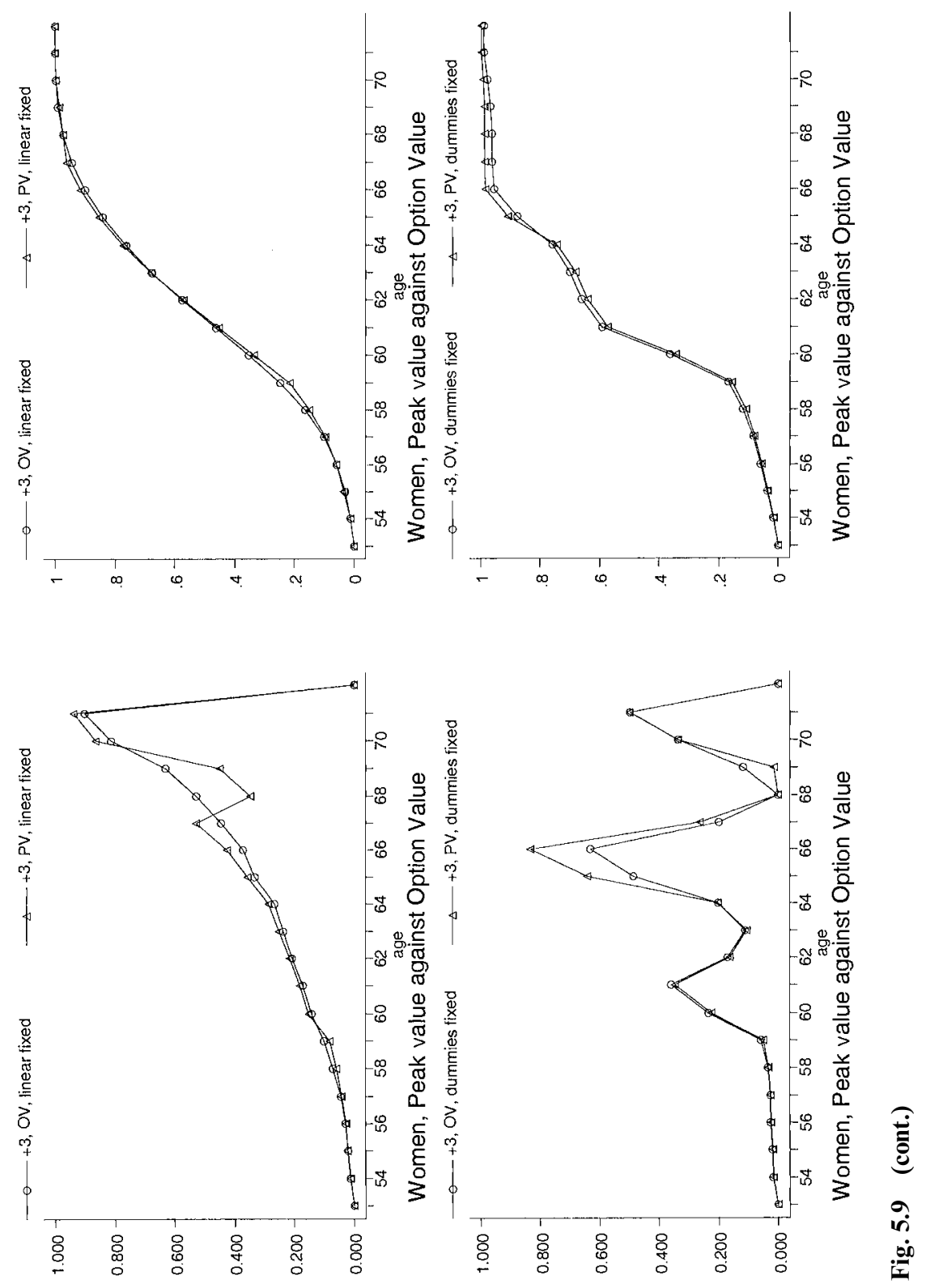

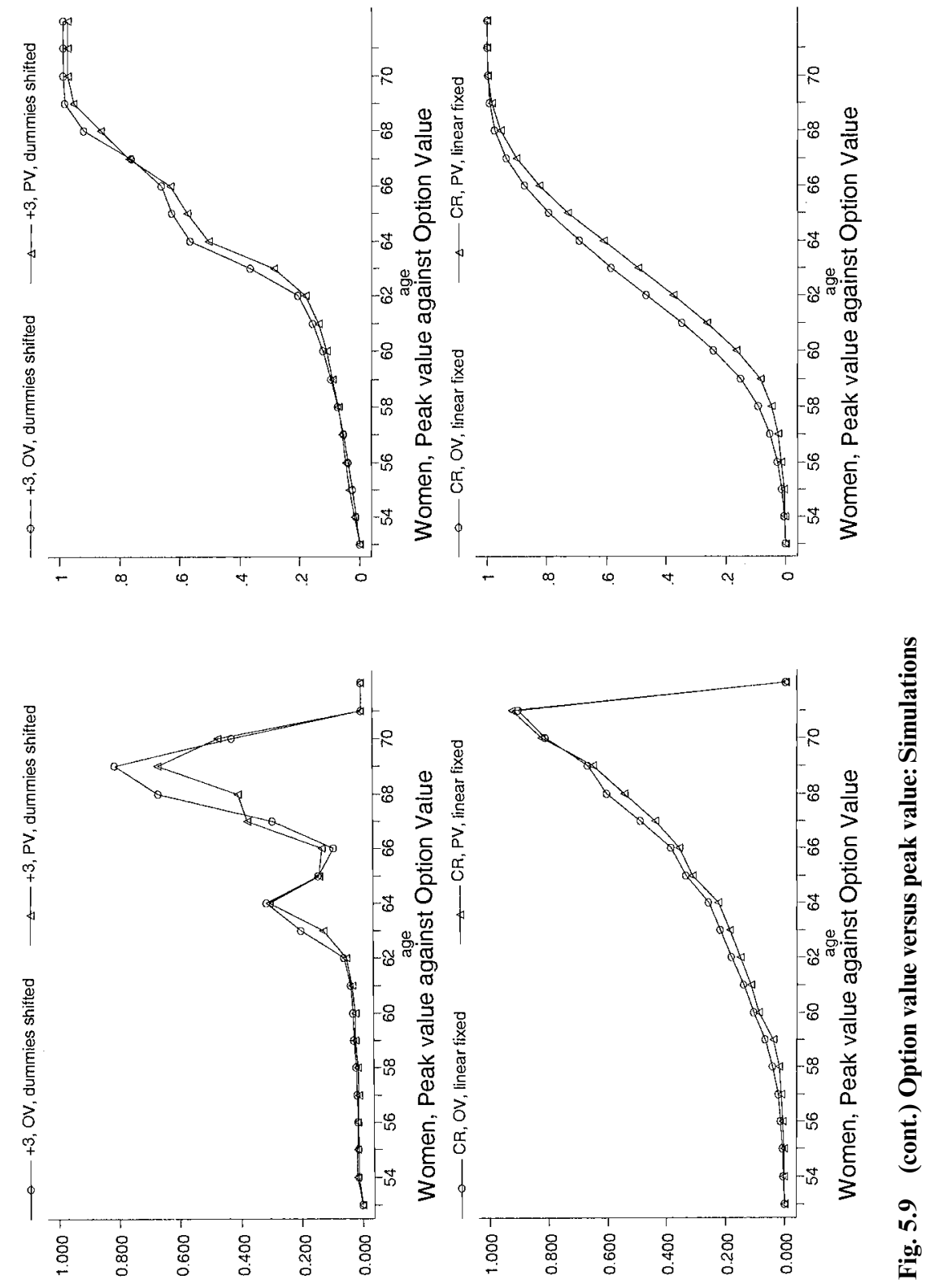

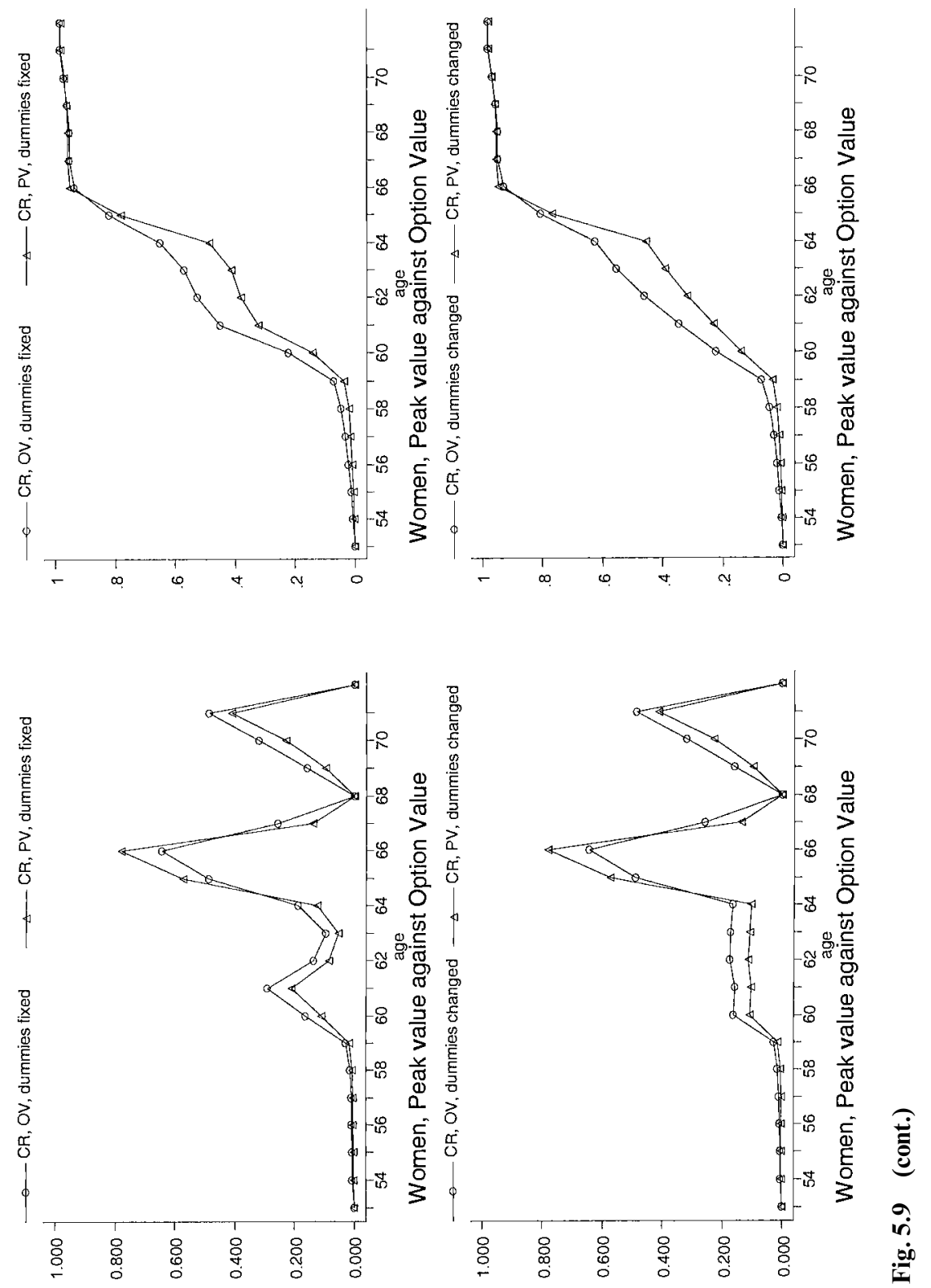

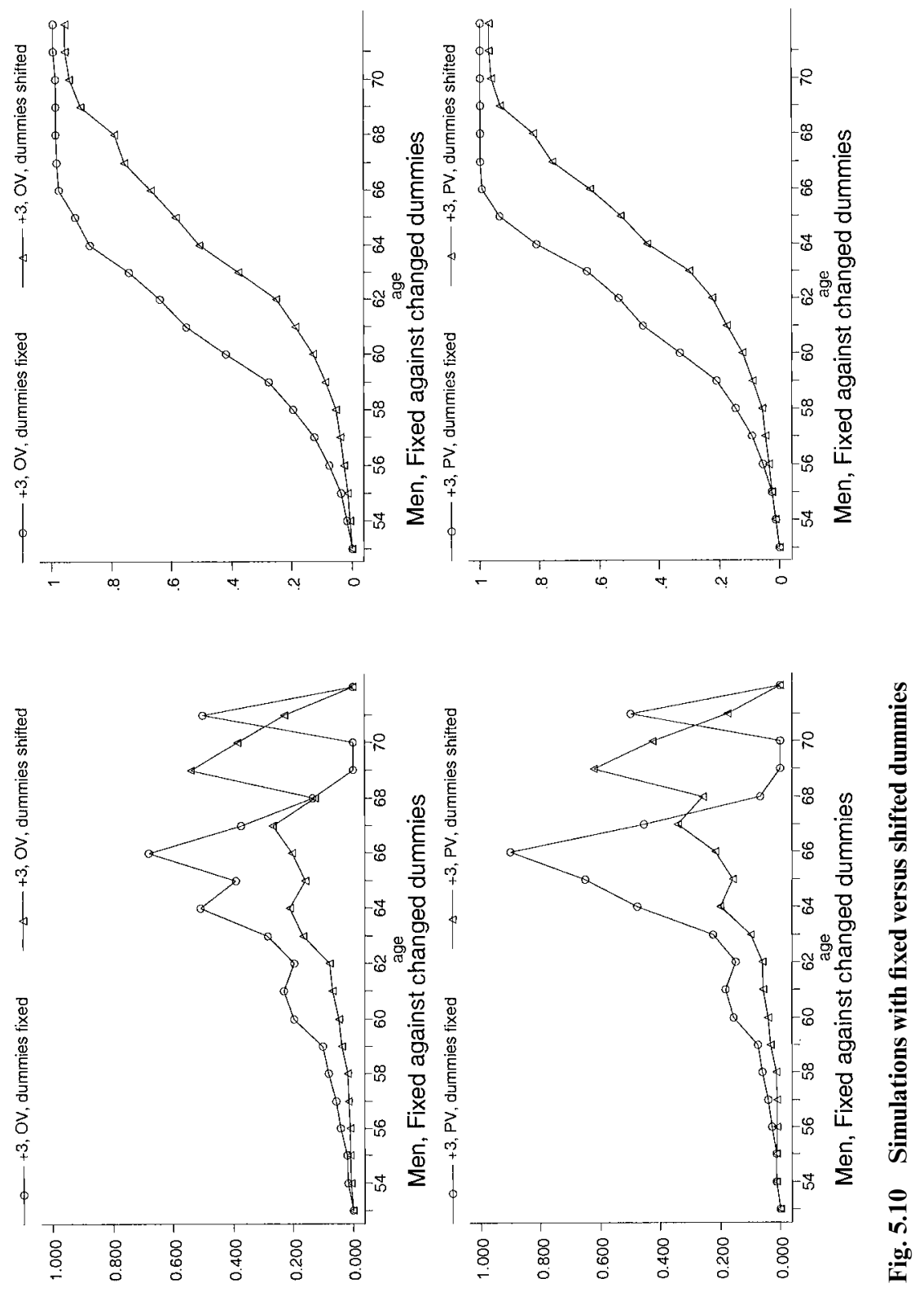

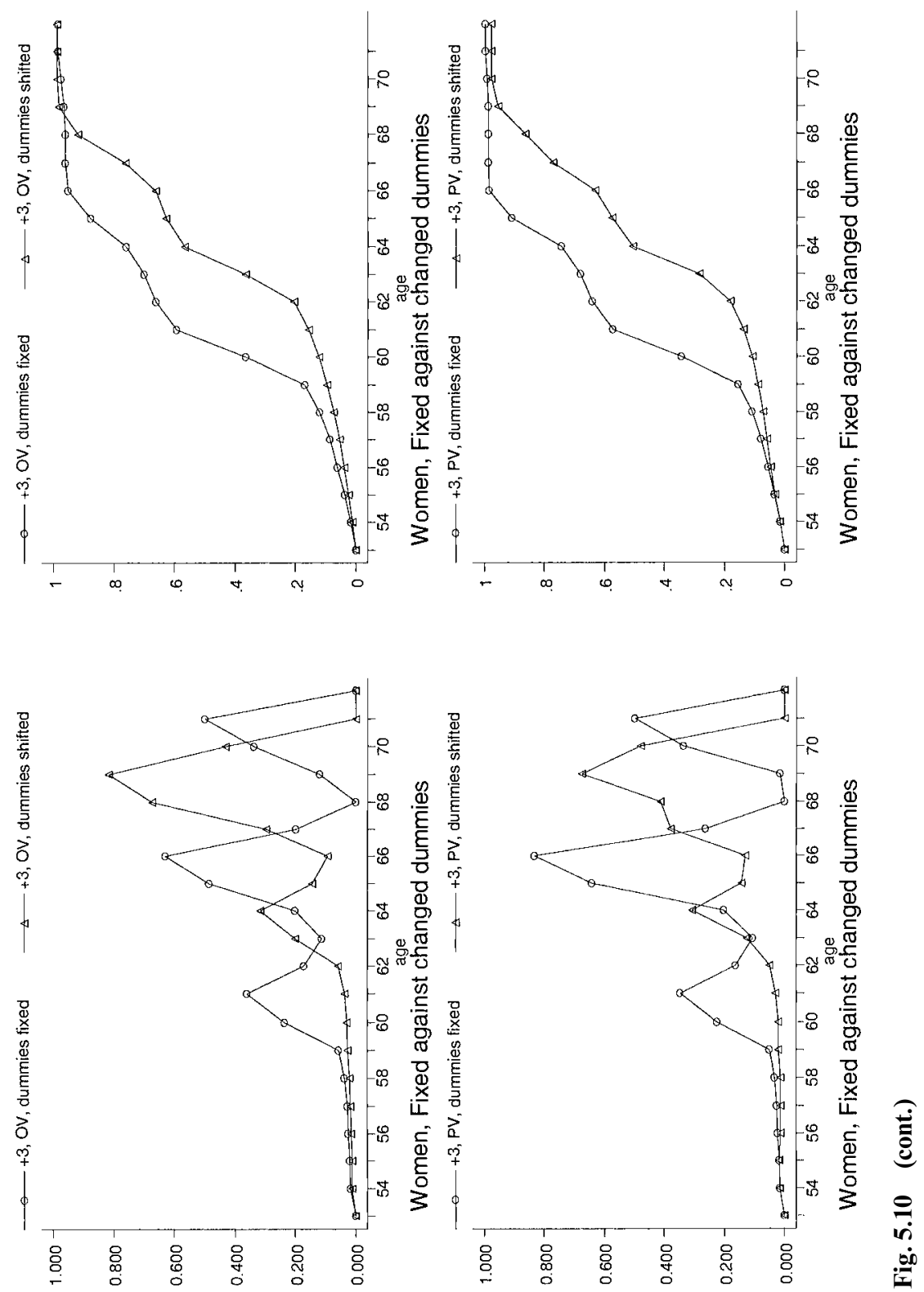


\section{Appendix}

Table 5A.1

Sample Hazard Rates

\begin{tabular}{|c|c|c|c|c|c|c|c|c|c|c|}
\hline \multirow[b]{2}{*}{ Age } & \multicolumn{5}{|c|}{ Men } & \multicolumn{5}{|c|}{ Women } \\
\hline & $N$ & Mean & SD & $\begin{array}{l}95 \% \\
\text { Lower } \\
\text { Bound }\end{array}$ & $\begin{array}{c}95 \% \\
\text { Upper } \\
\text { Bound }\end{array}$ & $N$ & Mean & SD & $\begin{array}{l}95 \% \\
\text { Lower } \\
\text { Bound }\end{array}$ & $\begin{array}{c}95 \% \\
\text { Upper } \\
\text { Bound }\end{array}$ \\
\hline 54 & 861 & 0.013 & 0.004 & 0.005 & 0.020 & 470 & 0.017 & 0.006 & 0.005 & 0.029 \\
\hline 55 & 889 & 0.015 & 0.004 & 0.007 & 0.023 & 477 & 0.019 & 0.006 & 0.007 & 0.031 \\
\hline 56 & 868 & 0.026 & 0.005 & 0.016 & 0.037 & 433 & 0.025 & 0.008 & 0.011 & 0.040 \\
\hline 57 & 804 & 0.041 & 0.007 & 0.027 & 0.055 & 400 & 0.025 & 0.008 & 0.010 & 0.040 \\
\hline 58 & 721 & 0.060 & 0.009 & 0.042 & 0.077 & 359 & 0.033 & 0.009 & 0.015 & 0.052 \\
\hline 59 & 629 & 0.073 & 0.010 & 0.053 & 0.094 & 314 & 0.051 & 0.012 & 0.026 & 0.075 \\
\hline 60 & 528 & 0.155 & 0.016 & 0.124 & 0.186 & 251 & 0.219 & 0.026 & 0.168 & 0.271 \\
\hline 61 & 406 & 0.185 & 0.019 & 0.147 & 0.223 & 161 & 0.348 & 0.038 & 0.273 & 0.422 \\
\hline 62 & 294 & 0.146 & 0.021 & 0.106 & 0.187 & 88 & 0.159 & 0.039 & 0.081 & 0.237 \\
\hline 63 & 218 & 0.225 & 0.028 & 0.169 & 0.281 & 68 & 0.103 & 0.037 & 0.029 & 0.177 \\
\hline 64 & 145 & 0.428 & 0.041 & 0.346 & 0.509 & 48 & 0.188 & 0.057 & 0.073 & 0.302 \\
\hline 65 & 73 & 0.315 & 0.055 & 0.206 & 0.424 & 37 & 0.486 & 0.083 & 0.318 & 0.655 \\
\hline 66 & 40 & 0.700 & 0.073 & 0.552 & 0.848 & 14 & 0.643 & 0.133 & 0.356 & 0.930 \\
\hline 67 & 7 & 0.429 & 0.202 & -0.066 & 0.923 & 7 & 0.286 & 0.184 & -0.166 & 0.737 \\
\hline 68 & 4 & 0.250 & 0.250 & -0.546 & 1.046 & 5 & 0.000 & 0.000 & 0.000 & 0.000 \\
\hline 69 & 4 & 0.000 & 0.000 & 0.000 & 0.000 & 6 & 0.167 & 0.167 & -0.262 & 0.595 \\
\hline 70 & 3 & 0.000 & 0.000 & 0.000 & 0.000 & 3 & 0.333 & 0.333 & -1.101 & 1.768 \\
\hline 71 & 2 & 0.500 & 0.500 & -5.853 & 6.853 & 2 & 0.500 & 0.500 & -5.853 & 6.853 \\
\hline 72 & 1 & 0.000 & • & • & $\bullet$ & 0 & $\bullet$ & • & • & $\bullet$ \\
\hline 73 & 2 & 0.000 & 0.000 & 0.000 & 0.000 & 0 & • & • & • & • \\
\hline 74 & 1 & 0.000 & • & • & $\bullet$ & 0 & • & • & • & • \\
\hline 75 & 0 & $\bullet$ & • & • & • & 0 & - & • & • & • \\
\hline
\end{tabular}

Note: $N=$ number of observations; $\mathrm{SD}=$ standard deviation. Dots indicate observations. 


\begin{tabular}{|c|c|c|c|c|c|}
\hline \multirow[b]{2}{*}{ Age } & \multirow[b]{2}{*}{ Sample } & \multicolumn{2}{|c|}{ Option Value Model } & \multicolumn{2}{|c|}{ Peak Value Model } \\
\hline & & Linear & Dummies & Linear & Dummies \\
\hline 53 & 0.000 & 0.000 & 0.000 & 0.000 & 0.000 \\
\hline 54 & 0.013 & 0.007 & 0.012 & 0.009 & 0.012 \\
\hline 55 & 0.015 & 0.013 & 0.014 & 0.016 & 0.014 \\
\hline 56 & 0.026 & 0.023 & 0.027 & 0.024 & 0.026 \\
\hline 57 & 0.041 & 0.039 & 0.041 & 0.039 & 0.041 \\
\hline 58 & 0.060 & 0.064 & 0.059 & 0.059 & 0.059 \\
\hline 59 & 0.073 & 0.100 & 0.076 & 0.088 & 0.075 \\
\hline 60 & 0.155 & 0.141 & 0.156 & 0.136 & 0.156 \\
\hline 61 & 0.185 & 0.182 & 0.181 & 0.181 & 0.182 \\
\hline 62 & 0.146 & 0.211 & 0.145 & 0.218 & 0.145 \\
\hline 63 & 0.225 & 0.258 & 0.225 & 0.285 & 0.255 \\
\hline 64 & 0.428 & 0.289 & 0.427 & 0.323 & 0.426 \\
\hline 65 & 0.315 & 0.310 & 0.316 & 0.280 & 0.326 \\
\hline 66 & 0.700 & 0.412 & 0.698 & 0.356 & 0.692 \\
\hline 67 & 0.429 & 0.424 & 0.425 & 0.437 & 0.426 \\
\hline 68 & 0.250 & 0.379 & 0.239 & 0.447 & 0.234 \\
\hline 69 & 0.000 & 0.507 & 0.000 & 0.537 & 0.000 \\
\hline 70 & 0.000 & 0.472 & 0.000 & 0.540 & 0.000 \\
\hline 71 & 0.500 & 0.550 & 0.500 & 0.623 & 0.500 \\
\hline 72 & 0.000 & 0.671 & 0.000 & 0.717 & 0.000 \\
\hline
\end{tabular}

Table 5A.3 Three-Year-Shift Reform: Simulated Hazard Rates (men)

\begin{tabular}{lccccccc}
\hline & \multicolumn{3}{c}{ Option Value Model } & & \multicolumn{3}{c}{ Peak Value Model } \\
\cline { 2 - 3 } Age & Linear & Dummies & Shifted & & Linear & Dummies & Shifted \\
\hline 53 & 0.000 & 0.000 & 0.000 & 0.000 & 0.000 & 0.000 \\
54 & 0.003 & 0.004 & 0.004 & 0.010 & 0.013 & 0.013 \\
55 & 0.005 & 0.004 & 0.005 & & 0.016 & 0.014 & 0.014 \\
56 & 0.008 & 0.009 & 0.006 & 0.024 & 0.028 & 0.012 \\
57 & 0.013 & 0.012 & 0.006 & 0.039 & 0.042 & 0.014 \\
58 & 0.023 & 0.018 & 0.008 & 0.059 & 0.059 & 0.015 \\
59 & 0.036 & 0.022 & 0.015 & 0.087 & 0.073 & 0.035 \\
60 & 0.050 & 0.046 & 0.017 & 0.107 & 0.080 & 0.034 \\
61 & 0.077 & 0.065 & 0.025 & 0.146 & 0.096 & 0.049 \\
62 & 0.097 & 0.052 & 0.025 & 0.179 & 0.072 & 0.051 \\
63 & 0.142 & 0.106 & 0.065 & 0.237 & 0.120 & 0.088 \\
64 & 0.179 & 0.265 & 0.074 & 0.284 & 0.304 & 0.094 \\
65 & 0.222 & 0.211 & 0.065 & 0.328 & 0.475 & 0.075 \\
66 & 0.274 & 0.517 & 0.112 & 0.400 & 0.805 & 0.117 \\
67 & 0.265 & 0.240 & 0.224 & 0.351 & 0.203 & 0.187 \\
68 & 0.252 & 0.131 & 0.129 & 0.363 & 0.092 & 0.313 \\
69 & 0.387 & 0.000 & 0.482 & 0.465 & 0.000 & 0.674 \\
70 & 0.364 & 0.000 & 0.196 & 0.455 & 0.000 & 0.149 \\
71 & 0.493 & 0.432 & 0.179 & 0.559 & 0.316 & 0.077 \\
72 & 0.617 & 0.000 & 0.000 & 0.649 & 0.000 & 0.000 \\
\hline
\end{tabular}




\begin{tabular}{lccccccc}
\hline & \multicolumn{3}{c}{ Option Value Model } & & \multicolumn{3}{c}{ Peak Value Model } \\
\cline { 2 - 3 } Age & Linear & Dummies & Shifted & & Linear & Dummies & Shifted \\
\hline 53 & 0.000 & 0.000 & 0.000 & 0.000 & 0.000 & 0.000 \\
54 & 0.006 & 0.009 & 0.004 & 0.010 & 0.014 & 0.013 \\
55 & 0.010 & 0.010 & 0.004 & & 0.017 & 0.015 & 0.014 \\
56 & 0.016 & 0.018 & 0.009 & 0.026 & 0.034 & 0.028 \\
57 & 0.026 & 0.026 & 0.012 & & 0.040 & 0.047 & 0.042 \\
58 & 0.041 & 0.035 & 0.018 & 0.060 & 0.064 & 0.059 \\
59 & 0.062 & 0.042 & 0.022 & 0.085 & 0.071 & 0.073 \\
60 & 0.086 & 0.088 & 0.046 & 0.099 & 0.068 & 0.080 \\
61 & 0.137 & 0.130 & 0.065 & 0.139 & 0.088 & 0.096 \\
62 & 0.187 & 0.123 & 0.052 & 0.175 & 0.069 & 0.072 \\
63 & 0.269 & 0.238 & 0.106 & 0.241 & 0.127 & 0.120 \\
64 & 0.341 & 0.497 & 0.265 & 0.293 & 0.333 & 0.304 \\
65 & 0.401 & 0.426 & 0.211 & 0.353 & 0.524 & 0.475 \\
66 & 0.456 & 0.741 & 0.517 & 0.421 & 0.847 & 0.805 \\
67 & 0.398 & 0.394 & 0.240 & 0.404 & 0.331 & 0.203 \\
68 & 0.350 & 0.209 & 0.131 & 0.410 & 0.147 & 0.092 \\
69 & 0.498 & 0.000 & 0.000 & 0.525 & 0.000 & 0.000 \\
70 & 0.539 & 0.000 & 0.000 & 0.626 & 0.000 & 0.000 \\
71 & 0.602 & 0.564 & 0.432 & 0.689 & 0.690 & 0.316 \\
72 & 0.724 & 0.000 & 0.000 & 0.781 & 0.000 & 0.000 \\
\hline
\end{tabular}

Table 5A.5

Base Case: Empirical and Simulated Hazard Rates (women)

\begin{tabular}{lcccccc}
\hline & & \multicolumn{2}{c}{ Option Value Model } & & \multicolumn{2}{c}{ Peak Value Model } \\
\cline { 3 - 4 } Age & Sample & Linear & Dummies & & Linear & Dummies \\
\hline 53 & 0.000 & 0.000 & 0.000 & 0.000 & 0.000 \\
54 & 0.017 & 0.011 & 0.016 & 0.013 & 0.016 \\
55 & 0.019 & 0.018 & 0.018 & & 0.021 & 0.018 \\
56 & 0.025 & 0.028 & 0.024 & & 0.026 & 0.024 \\
57 & 0.025 & 0.043 & 0.024 & & 0.040 & 0.024 \\
58 & 0.033 & 0.067 & 0.033 & & 0.059 & 0.032 \\
59 & 0.051 & 0.095 & 0.052 & & 0.079 & 0.051 \\
60 & 0.219 & 0.137 & 0.221 & 0.150 & 0.222 \\
61 & 0.348 & 0.16 & 0.346 & & 0.179 & 0.346 \\
62 & 0.159 & 0.200 & 0.160 & & 0.215 & 0.162 \\
63 & 0.103 & 0.229 & 0.105 & & 0.250 & 0.107 \\
64 & 0.188 & 0.257 & 0.185 & 0.280 & 0.186 \\
65 & 0.486 & 0.324 & 0.488 & & 0.256 & 0.486 \\
66 & 0.643 & 0.377 & 0.644 & 0.262 & 0.645 \\
67 & 0.286 & 0.523 & 0.303 & 0.561 & 0.313 \\
68 & 0.000 & 0.634 & 0.000 & 0.640 & 0.000 \\
69 & 0.167 & 0.681 & 0.180 & 0.704 & 0.167 \\
70 & 0.333 & 0.822 & 0.337 & 0.873 & 0.337 \\
71 & 0.500 & 0.905 & 0.500 & 0.942 & 0.500 \\
72 & 0.000 & 0.000 & 0.000 & 0.000 & 0.000 \\
\hline
\end{tabular}




\begin{tabular}{lccccccc}
\hline & \multicolumn{3}{c}{ Option Value Model } & & \multicolumn{3}{c}{ Peak Value Model } \\
\cline { 2 - 3 } Age & Linear & Dummies & Shifted & & Linear & Dummies & Shifted \\
\hline 53 & 0.000 & 0.000 & 0.000 & 0.000 & 0.000 & 0.000 \\
54 & 0.006 & 0.007 & 0.007 & 0.013 & 0.017 & 0.017 \\
55 & 0.009 & 0.007 & 0.008 & & 0.021 & 0.019 & 0.019 \\
56 & 0.015 & 0.010 & 0.009 & 0.028 & 0.026 & 0.016 \\
57 & 0.022 & 0.009 & 0.009 & & 0.041 & 0.025 & 0.017 \\
58 & 0.034 & 0.011 & 0.010 & 0.060 & 0.033 & 0.018 \\
59 & 0.049 & 0.017 & 0.013 & & 0.081 & 0.052 & 0.029 \\
60 & 0.072 & 0.099 & 0.013 & 0.093 & 0.111 & 0.019 \\
61 & 0.098 & 0.198 & 0.015 & 0.120 & 0.212 & 0.024 \\
62 & 0.135 & 0.082 & 0.028 & 0.155 & 0.083 & 0.044 \\
63 & 0.167 & 0.05 & 0.121 & 0.187 & 0.050 & 0.110 \\
64 & 0.204 & 0.123 & 0.221 & 0.225 & 0.116 & 0.205 \\
65 & 0.283 & 0.421 & 0.101 & 0.272 & 0.518 & 0.067 \\
66 & 0.310 & 0.544 & 0.058 & 0.285 & 0.691 & 0.030 \\
67 & 0.401 & 0.134 & 0.220 & 0.346 & 0.057 & 0.111 \\
68 & 0.488 & 0.000 & 0.622 & 0.410 & 0.000 & 0.541 \\
69 & 0.580 & 0.071 & 0.781 & 0.511 & 0.023 & 0.794 \\
70 & 0.762 & 0.217 & 0.312 & 0.683 & 0.056 & 0.126 \\
71 & 0.870 & 0.391 & 0.000 & 0.814 & 0.136 & 0.000 \\
72 & 0.000 & 0.000 & 0.000 & 0.000 & 0.000 & 0.000 \\
\hline
\end{tabular}

Table 5A.7

Common Reform: Simulated Hazard Rates (women)

\begin{tabular}{lccccccc}
\hline & \multicolumn{3}{c}{ Option Value Model } & & \multicolumn{3}{c}{ Peak Value Model } \\
\cline { 2 - 3 } Age & Linear & Dummies & Shifted & & Linear & Dummies & Shifted \\
\hline 53 & 0.000 & 0.000 & 0.000 & 0.000 & 0.000 & 0.000 \\
54 & 0.003 & 0.004 & 0.007 & 0.007 & 0.008 & 0.017 \\
55 & 0.005 & 0.004 & 0.007 & & 0.010 & 0.007 & 0.019 \\
56 & 0.009 & 0.006 & 0.010 & 0.015 & 0.012 & 0.026 \\
57 & 0.013 & 0.004 & 0.009 & 0.022 & 0.010 & 0.025 \\
58 & 0.021 & 0.005 & 0.011 & 0.032 & 0.012 & 0.033 \\
59 & 0.034 & 0.010 & 0.017 & 0.048 & 0.022 & 0.052 \\
60 & 0.053 & 0.067 & 0.099 & 0.081 & 0.092 & 0.111 \\
61 & 0.074 & 0.145 & 0.198 & 0.104 & 0.177 & 0.212 \\
62 & 0.108 & 0.058 & 0.082 & 0.135 & 0.065 & 0.083 \\
63 & 0.138 & 0.037 & 0.054 & 0.161 & 0.036 & 0.050 \\
64 & 0.175 & 0.096 & 0.123 & 0.193 & 0.086 & 0.116 \\
65 & 0.259 & 0.380 & 0.420 & 0.271 & 0.515 & 0.518 \\
66 & 0.268 & 0.471 & 0.544 & 0.277 & 0.675 & 0.691 \\
67 & 0.346 & 0.090 & 0.134 & 0.325 & 0.048 & 0.057 \\
68 & 0.415 & 0.000 & 0.000 & 0.375 & 0.000 & 0.000 \\
69 & 0.516 & 0.041 & 0.071 & 0.467 & 0.015 & 0.023 \\
70 & 0.688 & 0.126 & 0.217 & 0.592 & 0.024 & 0.056 \\
71 & 0.818 & 0.277 & 0.391 & 0.717 & 0.062 & 0.136 \\
72 & 0.000 & 0.000 & 0.000 & 0.000 & 0.000 & 0.000 \\
\hline
\end{tabular}




\section{References}

Birg, H., and A. Börsch-Supan. 1999. Für eine neue Aufgabenteilung zwischen gesetziclicher und privater Altersversorgung (A new division of labor between public and private pensions). Berlin: GDV.

Börsch-Supan, A. 1992. Population aging, social security design, and early retirement. Journal of Institutional and Theoretical Economics 148:533-57.

1995. Regional development, capital flows, and trade policies in an aging Europe. In Neue entwicklungen in der regionalökonomik (New developments in regional economics), ed. B. Gahlen, H. Hesse, and H. J. Ramser, 237-63.

- 1998. Germany: A social security system on the verge of collapse. In Redesigning social security, ed. H. Siebert, 129-59. Tübingen, Germany: J. C. B. Mohr.

- 2000a. A model under siege: A case study of the German retirement insurance system. The Economic Journal 110 (461): F24-45.

2000b. Data and research on retirement in Germany. Report for the National Academy of Sciences, Washington, D.C. University of Mannheim, Department of Economics. Mimeograph.

.2000c. Incentive effects of social security on labour force participation: Evidence in Germany and across Europe. Journal of Public Economics 78:25-49.

- 2001a. Blaupause für eine nachhaltige rentenreform (Blueprint for a sustainable pension reform). University of Mannheim, Department of Economics. Mimeograph.

- 2001b. Incentive effects of social security under an uncertain disability option. In Themes in the economics of aging, ed. D. A. Wise, 281-310. Chicago: University of Chicago Press.

Börsch-Supan, A., and P. Schmidt. 1996. Early retirement in East and West Germany. In Employment policy in the transition to free enterprise: German integration and its lessons for Europe, London, ed. R. Riphahn, D. Snower, and K. Zimmermann, 83-102. Heidelberg, Germany: Springer.

- 1998. Social security and declining labor force participation in Germany. American Economic Review 88 (2): 173-78.

1999. Social security and retirement in Germany. In International social security comparisons, ed. J. Gruber and D. A. Wise, 135-80. Chicago: University of Chicago Press.

Bundesministerium für Arbeit und Sozialordnung (BMA). 1997. Statistisches taschenbuch (Statistical handbook). Bonn, Germany: Bundespresseamt.

Burkhauser, R. 1991. An introduction to the German socio-economic panel for English speaking researchers. Syracuse University, Department of Economics. Mimeograph.

Casmir, B. 1989. Staatliche rentenversicherungssysteme im internationalen Vergleich (Public pensions: An international comparison). Frankfurt, Germany: Lang.

Coile, Courtney. 1999. Retirement incentives and couples' retirement decisions, Ph.D. diss. MIT, Department of Economics.

Coile, Courtney, and Jonathan Gruber. 1999. Social security and retirement. MIT, Department of Economics. Mimeograph.

Gruber, J., and D. A. Wise, eds. 1999. Social security and retirement around the world. Chicago: University of Chicago Press.

Jacobs, K., M. Kohli, and K. Rein. 1990. Germany: The diversity of pathways. In Time for retirement: Comparative studies of early exit from the labor force, ed. M. Kohli, M. Rein, A. M. Guillemard, and H. van Gunsteren, 181-221. Cambridge: Cambridge University Press. 
Lumsdaine, R. L., J. H. Stock, and D. A. Wise. 1992. Three models of retirement: Computational complexity versus predictive validity. In Topics in the economics of aging, ed. D. A. Wise, 16-60. Chicago: University of Chicago Press.

Meghir, C., and E. Whitehouse. 1997. Labour market transitions and retirement of men in the UK. Journal of Econometrics 79:327-54.

Riphahn, Regina T. 1995. Disability retirement among German men in the 1980s. Ludwig Maximilians Universität. Münchner Wirtschaftswissenschaftliche Beiträge (Munich Economics Discussion Papers), no. 95-20. München, Germany.

Riphahn, Regina T., and P. Schmidt. 1995. Determinanten des ruhestandes: Lockt der ruhestand oder drängt der arbeitsmarkt (Determinants of retirement: Is leisure pulling or the labor market pushing)? Center for European Economic Research (ZEW) Discussion Paper no. 95-10. Mannheim, Germany.

Rust, J. 1990. Behavior of male workers at the end of the life cycle: An empirical analysis of states and controls. In Issues in the economics of aging, ed. D. A. Wise, 317-79. Chicago: University of Chicago Press.

Rust, J., and C. Phelan. 1997. How Social Security and Medicare affect retirement behavior in a world of incomplete markets. Econometrica 65 (4): 781-831.

Schmähl, W. 1991. Alterssicherung in der DDR und ihre umgestaltung im zuge des deutschen einigungsprozesses - einige verteilungspolitische aspekte (Pensions in the GDR and their changes during reunification-some distributional aspects). In Sozialpolitik im vereinten Deutschland (Social policy in a unified Germany), ed. G. Kleinhenz, 49-95. Berlin: Duncker and Humblot.

Schmidt, P. 1995. Die wahl des rentenalters-Theoretische und empirische analyse des rentenzugangsverhaltens in West- und Ostdeutschland (The choice of retirement age - theoretical and empirical analyses of retirement behavior in West and East Germany). Frankfurt, Germany: Lang.

Schnabel, R. 1998. Rates of return of the German pay-as-you-go pension system. Finanzarchiv N.F. 55 (3): 374-99.

. 1999. Opting out of social security: Incentives and participation in the German public pension system. SFB504-Discussion Paper no. 99-42. University of Mannheim, Department of Economics.

Siddiqui, S. 1997. The pension incentive to retire: Empirical evidence for West Germany. Journal of Population Economics 10 (4): 463-86.

Stock, J. H., and D. A. Wise. 1990. The pension inducement to retire: An option value analysis. In Issues in the economics of aging, ed. D. A. Wise, 205-30. Chicago: University of Chicago Press.

Sueyoshi, G. T. 1989. Social security and the determinants of full and partial retirement: A competing risk analysis. NBER Working Paper no. 3113. Cambridge, Mass.: National Bureau of Economic Research.

Verband Deutscher Rentenversicherungsträger (VDR). 1999. Die rentenversicherung in zeitreihen (German public pensions in time series). Frankfurt am Main, Germany: VDR. 
